\title{
The density-salinity relation of standard seawater
}

\author{
Hannes Schmidt ${ }^{1}$, Steffen Seitz $^{1}$, Egon Hassel ${ }^{2}$, and Henning Wolf ${ }^{1}$ \\ ${ }^{1}$ Physikalisch-Technische Bundesanstalt, Braunschweig, 38116, Germany \\ ${ }^{2}$ Lehrstuhl für Technische Thermodynamik, Universität Rostock, Rostock, 18051, Germany
}

Correspondence: Henning Wolf (henning.wolf@ptb.de)

Received: 18 August 2017 - Discussion started: 5 September 2017

Revised: 11 November 2017 - Accepted: 19 November 2017 - Published: 4 January 2018

\begin{abstract}
The determination of salinity by means of electrical conductivity relies on stable salt proportions in the North Atlantic Ocean, because standard seawater, which is required for salinometer calibration, is produced from water of the North Atlantic. To verify the long-term stability of the standard seawater composition, it was proposed to perform measurements of the standard seawater density. Since the density is sensitive to all salt components, a density measurement can detect any change in the composition. A conversion of the density values to salinity can be performed by means of a density-salinity relation. To use such a relation with a target uncertainty in salinity comparable to that in salinity obtained from conductivity measurements, a density measurement with an uncertainty of $2 \mathrm{~g} \mathrm{~m}^{-3}$ is mandatory. We present a new density-salinity relation based on such accurate density measurements. The substitution measurement method used is described and density corrections for uniform isotopic and chemical compositions are reported. The comparison of densities calculated using the new relation with those calculated using the present reference equations of state TEOS-10 suggests that the density accuracy of TEOS-10 (as well as that of EOS-80) has been overestimated, as the accuracy of some of its underlying density measurements had been overestimated. The new density-salinity relation may be used to verify the stable composition of standard seawater by means of routine density measurements.
\end{abstract}

\section{Introduction}

For almost 40 years, the salinity ${ }^{1}$ of seawater has been indirectly determined by means of electrical conductivity. Since the absolute conductivity cannot be measured as accurately as required for precise salinity measurements (Seitz et al., 2010), the conductivity has been measured relative to that of standard seawater ${ }^{2}$; the conversion to salinity is carried out by means of the (relative) conductivity-salinity relation PSS-78 (JPOTS, 1981a, b). In practice, this is achieved by calibrating salinometers and conductivity-temperaturedepth devices using standard seawater, which is diluted to obtain the conductivity of the potassium chloride standard (Culkin, 1986; Bacon et al., 2007) used as a conductivity reference. An unconditional prerequisite for the comparability of salinity measurements over long periods is, therefore, that the salt proportions in standard seawater are stable. Unfortunately, this cannot be guaranteed, as standard seawater is of natural origin.

Recently, the long-term comparability of salinity measurement results was discussed, with two main deficiencies being elaborated (Pawlowicz et al., 2016): a lack of traceability to a long-term stable and ubiquitous reference like the International System of Units (SI) and chemical composition variabilities in standard seawater. These variabilities are likely to increase in the coming decades, due especially to the absorption of carbon dioxide into the ocean resulting from accumulation in the atmosphere (Millero, 2007). Both of these deficiencies entail a risk of inconsistent long-term salinity val-

\footnotetext{
1 "Salinity" refers strictly to practical salinity unless there is an exact specification.

${ }^{2}$ Standard seawater recognized by the International Association for the Physical Sciences of the Oceans (IAPSO) prepared from seawater of the North Atlantic Ocean.
} 
ues. To remedy the deficiencies, Seitz et al. (2011) proposed to perform routine measurements of the standard seawater density. In practice, this would be achieved by determining the salinity of a standard seawater batch not only by conductivity measurement, but also by density measurement; the conversion to salinity is carried out in this second approach by means of a density-salinity relation. Since the salinity obtained from density is sensitive to all components of the standard seawater, a change in its composition would lead to an inconsistency of the "density salinity" and the "KCl salinity".

To obtain a reliable statement about the consistency of the density salinity and the $\mathrm{KCl}$ salinity, they have to be compared against the background of their uncertainties. The reproducibility of the $\mathrm{KCl}$ salinity is 0.0004 (Bacon et al., 2007). However, this reproducibility is only valid for the time of preparation (Seitz et al., 2010), as, during storage, glass container material dissolves in the seawater, which is mainly silicate (e.g. Poisson et al., 1978; Higgs and Ridout, 2011; Uchida et al., 2011). The uncertainty in the "conductivity salinity" obtained by means of a salinometer is at least 0.0022 (Le Menn, 2011), and requires freshly prepared standard seawater for calibration. The corresponding values in terms of density are $0.3 \mathrm{~g} \mathrm{~m}^{-3}$ (for 0.0004 ) und $1.8 \mathrm{~g} \mathrm{~m}^{-3}$ (for 0.0022). The present reference equation of state TEOS10 (IOC et al., 2010) summarizes the most accurate density measurements obtained from standard seawater conducted by Millero et al. (1976) and by Poisson et al. (1980). TEOS10 , which implicitly contains a density-salinity relation of standard seawater, predicts the density with an estimated uncertainty of at least $8 \mathrm{~g} \mathrm{~m}^{-3}$ (Feistel, 2008), which is significantly higher than $1.8 \mathrm{~g} \mathrm{~m}^{-3}$, but reflecting the measurement uncertainty in seawater density at that time.

In this article, a new density-salinity relation is presented, whereby the salinity can be determined by means of density measurement with an accuracy of up to 0.003 for salinities up to 35 , temperatures between 5 and $35^{\circ} \mathrm{C}$ and atmospheric pressure, which is similar to the accuracy achieved by salinometers. The density was determined by using the substitution method developed by Schmidt et al. (2016). Because the water-isotopic and salt-chemical compositions, as well as the air saturation, of the seawater samples changed during preparation, storage and measurement, corrections were applied to specify the seawater density for uniform conditions; these corrections are of the same order of magnitude as the measurement uncertainty and are therefore essential for high accuracy. The corrected density values were used to develop a density-salinity relation. The comparison of densities calculated by means of the new relation with those calculated by means of TEOS-10 suggests that TEOS-10 (as well as EOS-80) predicts densities significantly too high by up to $15 \mathrm{~g} \mathrm{~m}^{-3}$. The deviations increase systematically with salinity. A plausible explanation was found in the design of the flotation densimeter (Millero, 1967) that Millero et al. (1976) used for their measurements obtained from standard seawater.
The new density-salinity relation may be used to reliably verify the stable composition of standard seawater by means of routine density measurements. On the one hand, the determination of salinity by means of conductivity is retroactively ensured in case of consistency; on the other hand, in case of inconsistency, a need for action is demonstrated.

\section{Density measurements}

Determining salinity by means of conductivity measurement is supported by the relations of PSS-78. To develop the density-salinity relation in such a way that it is consistent with PSS-78, the density measurements have to be obtained from seawater whose salinity determination is consistent with the salinity determination of the seawater used to develop PSS-78. In addition to the consistency of salinity determination, the accuracy of the density measurement is decisive. The more accurate the density measurement is, the more accurately the salinity can be determined (by means of the density-salinity relation). To achieve an accuracy in the density salinity that is equal to that in the conductivity salinity, a density uncertainty of $2 \mathrm{~g} \mathrm{~m}^{-3}$ is required. To this end, substitution measurement with a vibrating-tube densimeter relative to a water reference had been proposed (Wolf, 2008) before a substitution method specifically for seawater was developed and validated (Schmidt et al., 2016).

In this section, the preparation of the seawater measured and the determination of its salinity are described. The consistency of the salinities determined in the present, which were used to develop the density-salinity relation, with the salinities determined in 1978, which were used to develop PSS-78, is discussed. The substitution method and the apparatus used for the density measurement are briefly outlined, as they have already been described in detail by Schmidt et al. The uncertainty in density is discussed with regard to the uncertainty in salinity obtained from a density measurement and the subsequent calculation by means of the densitysalinity relation.

\subsection{Substitution method}

In a substitution method, a sample (seawater) with an unknown density and a similar, well-known reference (water) are measured (ideally, at the same time) using the same measurement device (densimeter). Deviations in the measurement results caused, for example, by a drift or a temperature deviation can be corrected, as they cause similar effects on seawater and on water. As a result, the measured densities of seawater and water have similar deviations from their true value. The difference equation for calculation of the corrected density from the measurements obtained from seawater and water is

$\rho_{\text {subs }}^{\mathrm{SW}}-\rho_{\text {ref }}^{\mathrm{H}_{2} \mathrm{O}}=\rho_{\text {mes }}^{\mathrm{SW}}-\rho_{\text {mes }}^{\mathrm{H}_{2} \mathrm{O}}$, 
where $\rho_{\text {mes }}^{\mathrm{SW}}$ and $\rho_{\text {mes }}^{\mathrm{H}_{2} \mathrm{O}}$ are the measured seawater and water densities, and $\rho_{\text {subs }}^{\mathrm{SW}}$ and $\rho_{\text {ref }}^{\mathrm{H}_{2} \mathrm{O}}$ are the corrected seawater (substitution) density and the well-known water reference density. If the absolute seawater density is determined from a substitution measurement (by calculating $\rho_{\text {mes }}^{\mathrm{SW}}-\rho_{\text {mes }}^{\mathrm{H}_{2} \mathrm{O}}+$ $\rho_{\text {ref }}^{\mathrm{H}_{2} \mathrm{O}}$ ), the result includes the uncertainty in the water reference density. By contrast, if the seawater density relative to water is determined (by calculating $\rho_{\text {mes }}^{\mathrm{SW}}-\rho_{\text {mes }}^{\mathrm{H}_{2} \mathrm{O}}$ ), the reference uncertainty is not included.

The water reference density was calculated using the equation of state developed by Wagner and Pruß (2002). A description of the calculation is given in Appendix A. The reference density uncertainty is $1 \mathrm{~g} \mathrm{~m}^{-3}$ for atmospheric pressure, $10 \mathrm{~g} \mathrm{~m}^{-3}$ for pressures up to $10 \mathrm{MPa}$, and $30 \mathrm{~g} \mathrm{~m}^{-3}$ for up to $100 \mathrm{MPa}$. The uncertainty in a corrected seawater density resulting from a substitution measurement mainly depends on the uncertainty in the water reference density, but also on the similarity of seawater and water in terms of their relevant thermophysical properties, as well as on the stability and linear characteristics of the densimeter used. It should be noted that the linearity is regularly checked in measurements on reference liquids with densities between $700 \mathrm{~kg} \mathrm{~m}^{-3}$ and $1600 \mathrm{~kg} \mathrm{~m}^{-3}$; furthermore, the linearity was particularly validated in the seawater density range by means of comparison measurements against a hydrostatic weighing apparatus for both the densimeters used for atmospheric and high pressure; details have been given by Schmidt et al. (2016).

\subsection{Materials}

\subsubsection{Reference water}

The water used as the reference liquid in the substitution measurements was prepared using tap water from Braunschweig, Germany. It was purified using a reverse osmosis module, an ion exchanger, and a $0.2 \mu \mathrm{m}$ filter. Its purity was checked by measuring the water conductivity at the outlet of the filter; the conductivity at 20 to $25^{\circ} \mathrm{C}$ was always lower than $0.1 \mu \mathrm{S} \mathrm{cm}^{-1}$. The water was degassed by boiling it for half an hour under minimum power. Immediately afterwards, it was poured into borosilicate vessels that were sealed in a hot state. This water was used for measurements over the course of 1 week. The reference water-air saturation was $20 \%$ with an uncertainty of $10 \%$. The isotopic abundances of deuterium and of oxygen-18 against Vienna Standard Mean Ocean Water were -59 and $-8.5 \%$. The abundances were measured before and after degassing and no significant differences were found. Details that have been given by Schmidt et al. (2016) are complemented by the Supplement to this article.

\subsubsection{Seawater}

All seawater samples were obtained from Ocean Scientific International Ltd. (OSIL), Havant, UK, which also deter- mined the salinity values. Samples with salinities of 10, 30, and 35 were taken from batches 10L13, 30L15, and P153.

Additionally, diluted seawater with salinities of 5, 15, 20 , and 25 was studied. These seawater batches were prepared using the same procedure as that used for the standard batches with salinities 10 and 30: First, a large amount of natural seawater (as used for the preparation of standard seawater) was diluted with water until its salinity was approximately equal to the target salinity. The raw salinity was determined using a modified 8400B Autosal salinometer (Bacon et al., 2007). Then, for calibration, a set of five samples per salinity was obtained by means of weight dilution of standard seawater (from batch P154 with a salinity of 34.9962). The balance used had a readability of $0.1 \mathrm{mg}$ and was calibrated using weight standards traceable to the National Physical Laboratory, Teddington, UK (B. Childs, personal communication, 2017). The salinity was again determined by the Autosal salinometer, on the one hand, and by means of the weights of the standard seawater and the water used for dilution on the other hand. The deviations found between the salinometer salinities and the weight-calculated salinities were used as calibration offsets for the raw salinities of the diluted seawater.

The salinity homogeneity and calibration measurements yielded the values and corresponding standard deviations given in Table 1. The uncertainty in the salinity of standard seawater was adopted from Bacon et al. (2007). The uncertainty in the salinity of diluted seawater includes the standard deviations of homogeneity and calibration measurements, as well as the uncertainty in the salinity of standard seawater. The systematic uncertainty contributions of weighing and refilling are negligible compared to the standard deviations. The uncertainty in the salinity of dilute samples is 0.0006 , which corresponds to a density uncertainty of $0.5 \mathrm{~g} \mathrm{~m}^{-3}$.

\subsection{Apparatus}

Vibrating-tube densimeters (VTDs) were used for density measurements performed using the substitution method. The core of such a densimeter is a U-shaped tube that is fixed in place on both ends. This tube is filled with the liquid to be measured and then forced to oscillate; the resulting oscillation period is a measure of the liquid density. Since the vibrating tube can be easily accessed from the outside, liquids can be filled in and changed quickly. This feature, together with short-term stability, is necessary for the application of the substitution method. Since the seawater sample and water reference cannot be measured simultaneously, stability is important for the duration of the alternating measurements. Under these conditions, the drift of the densimeter can be quantified using the deviations from the reference density (of water) to correct the sample density (of seawater).

The set-up used for the density measurements at atmospheric pressure is outlined in Fig. 1a. It comprises a fully automated filling system, a VTD, and a peristaltic pump. The 
Table 1. Summary of the batches of the standard seawater samples.

\begin{tabular}{lrrr|rr|rrr}
\hline Date of manufacture & \multicolumn{3}{c}{ Salinity } & \multicolumn{2}{c}{ Homogeneity } & \multicolumn{3}{c}{ Calibration } \\
mm/yyyy & \multicolumn{1}{c}{$S$} & $U^{\mathrm{a}}$ & $v_{\mathrm{eff}}^{\mathrm{d}}$ & $\sigma^{\mathrm{b}}$ & $\nu^{\mathrm{e}}$ & $\sigma^{\mathrm{c}}$ & $\nu^{\mathrm{e}}$ & Reference \\
\hline $10 / 2011$ & 4.9958 & 0.0006 & 4 & 0.0000 & 4 & 0.0002 & 4 & $\mathrm{P} 154$ \\
$03 / 2011$ & 9.9887 & 0.0006 & 6 & $0.0001^{\mathrm{f}}$ & $4^{\mathrm{f}}$ & $0.0002^{\mathrm{f}}$ & $4^{\mathrm{f}}$ & $\mathrm{P} 153$ \\
$10 / 2011$ & 14.9999 & 0.0005 & 8 & 0.0001 & 4 & 0.0002 & 4 & $\mathrm{P} 154$ \\
$10 / 2011$ & 20.0009 & 0.0007 & 7 & 0.0001 & 4 & 0.0002 & 4 & $\mathrm{P} 154$ \\
$10 / 2011$ & 25.0047 & 0.0005 & 17 & 0.0001 & 4 & 0.0002 & 4 & $\mathrm{P} 154$ \\
$03 / 2011$ & 29.9689 & 0.0006 & 25 & $0.0001^{\mathrm{f}}$ & $4^{\mathrm{f}}$ & $0.0002^{\mathrm{f}}$ & $4^{\mathrm{f}}$ & $\mathrm{P} 153$ \\
$03 / 2011$ & 34.9917 & 0.0004 & $\infty$ & - & - & - & - & $\mathrm{P} 153$ \\
\hline
\end{tabular}

${ }^{a}$ Uncertainty calculated based on ${ }^{b},{ }^{c}$, and reference salinity (of standard seawater). ${ }^{b}$ Mean standard deviation of five samples from batches delivered. ${ }^{c}$ Mean standard deviation of the five samples used for calibration. ${ }^{\mathrm{d}}$ Effective degrees of freedom calculated based on those of homogeneity, calibration, and reference salinity. ${ }^{\mathrm{e}}$ Degrees of freedom. ${ }^{\mathrm{f}}$ Values are estimated.
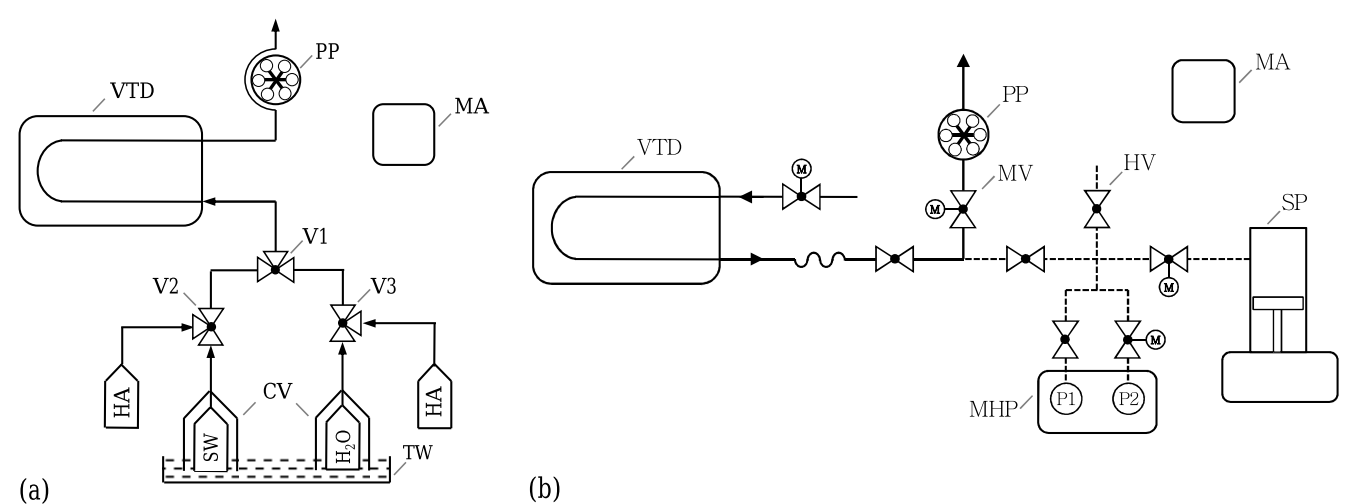

(b)

Figure 1. Set-up used to measure the seawater density (a) at atmospheric pressure and (b) at high pressures (Schmidt et al., 2016). The arrows indicate flow direction in capillary tubes. VTD - densimeter, PP - peristaltic pump, V1 - liquid switching valve, V2/V3 - air switching valves, $\mathrm{SW}$ - seawater, $\mathrm{H}_{2} \mathrm{O}$ - water, $\mathrm{HA}$ - humid air, CV - cover, TW - tap water, MA - manometer for atmospheric pressure, MV - motor-driven valve, HV - manual valve, SP - syringe pump, and MHP - manometer for high pressure (P1 - full-range sensor, P2 - low-range sensor). Dashed lines indicate tubes filled with oil. (C) Bureau International des Poids et Mesures. Reproduced by permission of IOP Publishing. All rights reserved.

filling system was created specifically for small filling volumes to allow more repetitions in the substitution measurements from a limited sample amount. To this end, a sequence of humid air bubbles is used to rinse the previous liquid out of the measuring cell. The bubbles of humid air are inserted into the sample filling tubes using the V2 and V3 valves in addition to the V1 valve to switch between the seawater sample and the water reference. The VTD used for the measurements is a DMA 5000M (Anton Paar GmbH, Graz, Austria). The peristaltic pump used to move the liquids is installed behind the VTD to avoid any interaction of the peristaltic tube material with the seawater or the water before the measurement.

The set-up used for density measurements at high pressures is illustrated in Fig. 1b. It uses an equal filling system to fill the water and seawater like the set-up used for atmospheric pressure. In addition to the filling system, the VTD, and the peristaltic pump, a pressurization part is installed between the VTD and the peristaltic pump. In this part, wherein the pressure is generated and measured, is a syringe pump filled with oil to prevent corrosion of the pressure sensors. The oil transmits the pressure generated in the syringe pump directly to the water without using a pressure transmitter. A long tube is installed between both parts (VTD and pressurization part) to avoid diffusion of oil into the measurement cell of the VTD. Two pressure sensors (P1 up to $14 \mathrm{MPa}$ and P2 up to $70 \mathrm{MPa}$ ) are used to increase the accuracy of the pressure measurement. The offsets of these sensors at atmospheric pressure are corrected by the values gained with the atmospheric pressure manometer before each measurement. The VTD used for the measurements at high pressures is a DMA HP (Anton Paar GmbH, Graz, Austria). Details that have been given by Schmidt et al. (2016) are complemented by the Supplement to this article.

The substitution measurements at atmospheric pressure were performed at a constant temperature. The water and seawater were filled and measured in alternation. The water densities measured were thus compared with the reference 
density; the deviations found were used to correct the seawater measurements.

The procedure for high pressures is similar to that used for atmospheric pressure; however, the liquid is not replaced during a high-pressure run at a constant temperature. Instead, the liquid is replaced after decreasing the pressure back to atmospheric conditions.

\subsection{Substitution densities}

The seawater density was measured in the temperature range of 5 to $35^{\circ} \mathrm{C}$. The densities were corrected to integer temperatures in ${ }^{\circ} \mathrm{C}$ and either to $101325 \mathrm{~Pa}$ or to integer pressures in bar, if the substitution density was determined for high pressures. The measured absolute seawater densities have uncertainties of $2 \mathrm{~g} \mathrm{~m}^{-3}$ for atmospheric pressure, $14 \mathrm{~g} \mathrm{~m}^{-3}$ for pressures up to $10 \mathrm{MPa}$, and $34 \mathrm{~g} \mathrm{~m}^{-3}$ for pressures up to $65 \mathrm{MPa}$. If stated relative to water, the seawater densities for high pressures have significantly smaller uncertainties, as they do not include the water reference uncertainty. The measured relative densities have uncertainties of 6 up to $14 \mathrm{~g} \mathrm{~m}^{-3}$ mainly depending on salinity.

Since the salinity uncertainty, which is $0.5 \mathrm{~g} \mathrm{~m}^{-3}$ in terms of density, is significant compared to the density measurement uncertainty for atmospheric pressure, it has to be considered in the development of the density-salinity relation. This had already been done at this point by adding the salinity uncertainty to the density measurement uncertainty.

\subsection{Comparability of salinity}

To determine salinity by means of conductivity, the PSS78 relations were developed based on five data sets ${ }^{3}$, which comprise conductivity measurements obtained from potassium chloride solutions and from standard seawater solutions with salinities of 2 to 42 . Standard seawater obtained from batch P79 was used to define the reference point at salinity 35 . To this end, the mass fraction of the potassium chloride solution which has the same conductivity as standard seawater (with salinity 35 ) was determined. These measurements were reported by Culkin and Smith (1980), Dauphinee et al. (1980a), and Poisson (1980a). Standard seawater obtained from batches P73, P75, and P79 was used to determine the conductivity of (diluted and concentrated standard seawater with) salinities $\neq 35$ relative to (seawater with) a salinity of 35 . These measurements were reported by Bradshaw and Schleicher (1980), Dauphinee et al. (1980b), and Poisson (1980b). For weighing, very precise balances were used, e.g. a Mettler M5 GD with a precision of $1 \mu \mathrm{g}$ for the potassium chloride or a Mettler B5 C1000 with a precision of $0.1 \mathrm{mg}$ for the solutions. The five data sets were used by Perkin and Lewis (1980) to find the coefficients of empirical correlations between salinity and (relative) conductivity that

\footnotetext{
${ }^{3}$ All publications cited here were also reprinted together (JPOTS, 1981b).
}

set PSS-78. The standard deviations of these fits are 0.0007 for atmospheric pressure and 0.0015 for high pressures and correspond to uncertainties of 0.0014 and 0.003 (Le Menn, 2011).

Both the salinities of the samples used to develop the conductivity-salinity relation PSS-78 and the salinities of the samples used to develop the density-salinity relation were thus determined by weighing measurements. If a relation between density and conductivity is set using both relations, then both (relation) uncertainties have to be taken into account. It should be noted that the density-conductivity relation is only valid if standard seawater is consistent in its composition. Conversely, this relation can therefore be used to check the standard seawater composition.

The uncertainty in a salinity determined by means of conductivity measurement that is supported by PSS-78 is (in a best-case scenario) 0.0022 using a laboratory salinometer and 0.0034 using a conductivity-temperature-depth device (Le Menn, 2011). These uncertainties are 2 and $3 \mathrm{~g} \mathrm{~m}^{-3}$ in terms of density. The accuracy of the seawater densities for atmospheric pressure fulfils these criteria, both in absolute terms and relative to the water reference. In the high-pressure range, it is currently not possible to achieve a comparable accuracy in absolute density using the substitution method and a water reference, as here, the uncertainty in the water reference density is too high. This can be circumvented by stating the seawater density relative to water.

Since the aim of developing the density-salinity relation was to determine the salinity by measuring density with higher accuracy than by measuring conductivity, a relative density-salinity relation was developed instead of an $a b$ solute density-salinity relation. The accuracy of a salinity that is determined by measuring density at high pressure and subsequent calculation using the (relative) densitysalinity relation is thus comparable to the salinity accuracy of conductivity-temperature-depth devices.

\section{Density corrections}

Standard seawater is prepared using natural seawater taken from the North Atlantic Ocean. To adjust the required salinity, the natural seawater is diluted with water prepared using groundwater taken from the British mainland; since the groundwater is isotopically depleted, the isotopic water composition of the natural seawater changes during dilution. After preparation, the seawater is poured into borosilicate glass vessels for delivery; these vessels are not completely inert against seawater. Since the seawater was stored in these vessels until the density measurements were made, glass material was dissolved into the seawater, changing the chemical composition by mainly increasing the dissolved silicate.

For the substitution measurements, the seawater was taken directly from these vessels and pumped into the substitution densimeter, where the temperature is altered; since the 
seawater was air-saturated at $20^{\circ} \mathrm{C}$ in the vessels before being pumped into the densimeter, the air saturation changed in measurements at other temperatures. Since the seawater density is significantly affected by these changes compared to the measurement uncertainty of $2 \mathrm{~g} \mathrm{~m}^{-3}$, it is necessary to apply corrections to uniform isotopic water and chemical composition, as well as to uniform air saturation.

In this section, corrections for these density effects to the following uniform conditions are presented: the hydrogendeuterium (H-D) and oxygen- 16,17 , and $18\left({ }^{16} \mathrm{O}-{ }^{17} \mathrm{O}-{ }^{18} \mathrm{O}\right)$ isotopic composition of Vienna Standard Mean Ocean Water (VSMOW), the initial chemical composition of the seawater before pouring (especially the silicate content), and air saturation, which depends on temperature. The corrections presented had been applied to the measured substitution seawater densities before the density-salinity relation was developed, thereby enabling uniform conditions and thus consistency.

\subsection{Isotopic composition}

Water shows a variation in its isotopic composition. The natural variation comprises the $\mathrm{H}-\mathrm{D}$ relation and the ${ }^{16} \mathrm{O}-{ }^{17} \mathrm{O}-$ ${ }^{18} \mathrm{O}$ relation. The isotopic abundance of a water sample is usually stated relative to that of the reference material VSMOW, whose isotopic composition is based on a mixture of ocean waters (IAEA, 2006). The D isotopic abundance (as well as the ${ }^{18} \mathrm{O}$ abundance) is thus expressed as the ratio of the amount-of-substance ratio of $\mathrm{D}$ and $\mathrm{H}$ in the sample to the respective ratio in VSMOW, $\delta_{\mathrm{D}}$ :

$\delta_{\mathrm{D}}=\left[\frac{\mathrm{D}}{\mathrm{H}}\right]^{\text {Sample }} /\left[\frac{\mathrm{D}}{\mathrm{H}}\right]^{\text {VSMOW }}-1$.

The ${ }^{17} \mathrm{O}$ abundance is usually not monitored, as it is very small compared to the ${ }^{18} \mathrm{O}$ abundance. In Earth's deep ocean layers, the isotopic composition varies by up to $4 \%$ in $\mathrm{D}$ and $0.3 \%$ in ${ }^{18} \mathrm{O}$, whereas in the surface ocean layers, these variations are up to 35 and $3 \%$ (Ferronsky and Polyakov, 2012) due to precipitation. A variation in the isotopic abundance affects the density directly: The corresponding variations are $0.1 \mathrm{~g} \mathrm{~m}^{-3}$ for the deep ocean and $1.3 \mathrm{~g} \mathrm{~m}^{-3}$ for the surface ocean if calculated using Eq. (A2) given in Appendix A. Isotopic composition variations in the water of the pedosphere are even more significant.

The $\mathrm{D}$ and ${ }^{18} \mathrm{O}$ isotopic abundances $\delta_{\mathrm{D}}$ and $\delta_{18}$ in the natural seawater that was used as the raw material for the diluted seawater preparation at the area of sampling were measured in 1972 and made available by Ostlund et al. (1987). The water which is deionized and used for dilution of the natural seawater (N. Higgs, personal communication, 2011) is tap water from Havant, UK, where the supplier of the IAPSO SSW is located. Darling et al. (2003) analysed the isotopic composition of freshwaters in the British Isles. They used isotope measurement data collected from around 1978 to 2003, in- cluding in the region from which the water for dilution was taken. The relevant values and uncertainties given by Ostlund et al. and Darling et al. are given in Table 2. The equations used to calculate the isotopic abundances of the diluted seawater after mixing standard seawater with water can be derived from the amount-of-substance balance of the isotope considered. For $\mathrm{D}$ and ${ }^{18} \mathrm{O}$, the equations derived are

$\delta_{\mathrm{D}}^{\mathrm{DSW}}=\frac{\left(\delta_{\mathrm{D}}^{\mathrm{H}_{2} \mathrm{O}}+1\right) \cdot m^{\mathrm{H}_{2} \mathrm{O}}+\left(\delta_{\mathrm{D}}^{\mathrm{SSW}}+1\right) \cdot m^{\mathrm{SSW}} \cdot\left(1-S_{\mathrm{A}}\right)}{m^{\mathrm{H}_{2} \mathrm{O}}+m^{\mathrm{SSW}} \cdot\left(1-S_{\mathrm{A}}\right)}$

and

$\delta_{18}^{\mathrm{DSW}}=\frac{\left(\delta_{18}^{\mathrm{H}_{2} \mathrm{O}}+1\right) \cdot m^{\mathrm{H}_{2} \mathrm{O}}+\left(\delta_{18}^{\mathrm{SSW}}+1\right) \cdot m^{\mathrm{SSW}} \cdot\left(1-S_{\mathrm{A}}\right)}{m^{\mathrm{H}_{2} \mathrm{O}}+m^{\mathrm{SSW}} \cdot\left(1-S_{\mathrm{A}}\right)}$,

where "DSW" refers to diluted seawater (after mixing) and $S_{\mathrm{A}}=S_{\mathrm{R}}=35.16504 / 35 \cdot S_{\mathrm{P}} \cdot\left(\mathrm{g} \mathrm{kg}^{-1}\right)$ is the absolute salinity of standard seawater, which is assumed to be equal to the reference salinity of IAPSO SSW according to the recommendation of Millero et al. (2008). The calculated isotopic abundance values and corresponding uncertainties of the seawater samples used for the density measurements are given in Table 2. For calculation of the uncertainty, only the isotopic abundances of the water and seawater were taken into account, as the other contributions are insignificant (for example, the salinity of the natural seawater, which is diluted, may differ by multiple $\mathrm{g} \mathrm{kg}^{-1}$ without affecting $\delta_{\mathrm{D}}^{\mathrm{DSW}}$ and $\delta_{18}^{\mathrm{DSW}}$ significantly).

The density difference due to the isotopic abundance change during preparation, $\Delta \rho_{\mathrm{prep}}^{\mathrm{SW}}$, is estimated using Eq. (A2), where $\Delta \delta_{\mathrm{D}}=\delta_{\mathrm{D}}^{\mathrm{DSW}}-\delta_{\mathrm{D}}^{\mathrm{SSW}}$ and $\Delta \delta_{18}=\delta_{18}^{\mathrm{DSW}}-$ $\delta_{18}^{\mathrm{SSW}}$ are inserted for this purpose. Following this procedure, the isotopic abundance effect on density is assumed to be the same for seawater as for water at $T_{\rho_{\max }}=3.98^{\circ} \mathrm{C}$ and $p_{0}=101325 \mathrm{~Pa}$ and is calculated relative to the isotopic composition of IAPSO SSW. $\Delta \rho \rho_{\text {prep }}^{\mathrm{SW}}$ is approximated by

$\frac{\Delta \rho_{\text {prep }}^{\mathrm{SW}}\left(S, T_{\rho_{\max }}, p_{0}\right)}{\mathrm{g} \mathrm{m}^{-3}}=-0.0700 \cdot S+2.4577$,

where $\Delta \rho_{\text {prep }}^{\mathrm{SW}}(S, T, p) \approx \Delta \rho_{\text {prep }}^{\mathrm{SW}}\left(S, T_{\rho_{\max }}, p_{0}\right)$, and $S, T$, and $p$ are the salinity, temperature, and (absolute) pressure, respectively. The uncertainty in $\Delta \rho_{\text {prep }}^{\mathrm{SW}}$ is estimated to be $0.3 \mathrm{~g} \mathrm{~m}^{-3}$; uncertainties in the isotopic abundances are insignificant.

$\Delta \rho_{\text {prep }}^{\mathrm{SW}}$ is illustrated in Fig. 2. The more water is used for dilution, the more the density decreases, as the water is depleted in heavy isotopes compared to seawater. The density difference caused by the difference between the isotopic composition of VSMOW and that of IAPSO SSW (which is given in Table 2), $\Delta \rho_{\text {iso }}^{\mathrm{SW}}$, is $0.3 \mathrm{~g} \mathrm{~m}^{-3}$.

\subsection{Chemical composition}

The seawater used for the measurements was stored in $230 \mathrm{~mL}$ borosilicate glass vessels (Bacon et al., 2007) from 
Table 2. Isotopic abundances of water and seawater (NSW - natural, DSW - diluted).

\begin{tabular}{lrrrrrl}
\hline Type & $S$ & $\begin{array}{r}\delta_{\mathrm{D}} \\
\%\end{array}$ & $\begin{array}{r}U \\
\% 0\end{array}$ & $\begin{array}{r}\delta_{18} \\
\% 0\end{array}$ & $\begin{array}{l}U \\
\% 0\end{array}$ & Source \\
- & - & & & \\
\hline $\mathrm{NSW}$ & 36.4 & 6.8 & $2.0^{*}$ & 1.06 & $0.20^{*}$ & Ostlund et al. (1987) \\
$\mathrm{H}_{2} \mathrm{O}$ & - & -40.0 & 2.0 & -6.50 & 0.20 & Darling et al. (2003) \\
$\mathrm{DSW}$ & 5 & -33.8 & 1.8 & -5.50 & 0.18 & - \\
$\mathrm{DSW}$ & 10 & -27.5 & 1.6 & -4.48 & 0.16 & - \\
$\mathrm{DSW}$ & 15 & -21.1 & 1.4 & -3.45 & 0.14 & - \\
$\mathrm{DSW}$ & 20 & -14.7 & 1.4 & -2.42 & 0.14 & - \\
DSW & 25 & -8.2 & 1.6 & -1.37 & 0.16 & - \\
DSW & 30 & -1.7 & 1.6 & -0.32 & 0.16 & - \\
IAPSO SSW & 35 & 4.9 & 2.0 & 0.76 & 0.20 & - \\
\hline
\end{tabular}

* Value is estimated

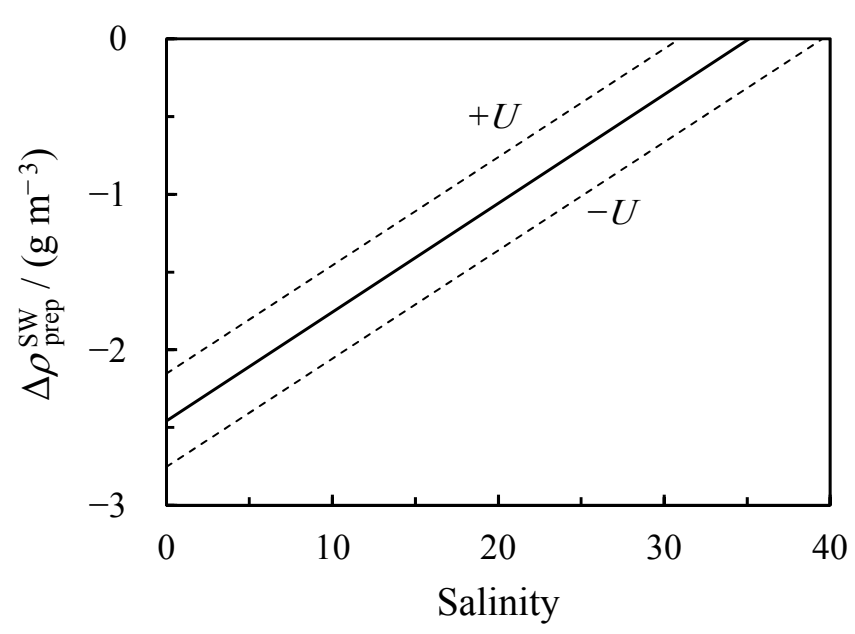

Figure 2. Density difference $\Delta \rho \rho_{\mathrm{prep}}^{\mathrm{SW}}$ caused by isotopic water composition change (relative to IAPSO SSW) during preparation. $U-$ estimated uncertainty.

the time of preparation at OSIL to the time of measurement. During this time, glass material that dissolved into the seawater has significantly altered the chemical composition, and thus the density.

\subsubsection{Silicate content of standard seawater}

Uchida et al. (2011) analysed the silicate increase in standard seawater delivered by OSIL that was stored in the vessels mentioned above. The silicate increase is related to the dissolution of silica from the glass vessel material. Uchida et al. measured the silicate molality of samples from batches P144 to P152 depending on their storage time. These data were used to estimate the initial silicate molality of the standard seawater used for the density measurements $b_{0}(S=35)$ after it had been prepared, and directly before it was poured into the vessels: $16.5 \mu \mathrm{mol} \mathrm{kg}^{-1}$ with a corresponding estimated uncertainty of $20 \%$. This silicate molality - which, in terms of conductivity, is insignificant - agrees well with that of standard seawater of batches up to P71 (Poisson et al., 1978) that were analysed shortly before the conductivity measurements of batch P75 and P79 seawater to develop PSS-78.

\subsubsection{Silicate content of the samples used for density measurements}

The silicate concentrations of some DSW samples from the batches with salinities of $5,10,15,20,25$, and 30 were measured shortly after all density measurements had been performed. The silicate concentration was measured at the Alfred-Wegener-Institut, Helmholtz-Zentrum für Polar- und Meeresforschung in Bremerhaven, Germany, using an Evolution III flow-through spectrophotometer (Alliance Instruments GmbH, Salzburg, Austria) according to Grasshoff et al. (1999). The device was calibrated before, between, and after the DSW sample measurements by measuring Merck Millipore Certipur silicon standard solutions (Merck KGaA, Darmstadt, Germany), which had a salinity of 36 and reference concentrations of around 7 and $50 \mu \mathrm{mol} \mathrm{L}^{-1}$.

The silicate concentration values of the DSW samples were converted to the molality values that are given in Table 3 , including the corresponding storage time. The silicate molality of the seawater that had salinities of 10,30 , and 35 is higher than that of the other batches, as it was stored longer in the vessels (see Table 1 for details).

The reproducibility of a silicate concentration measurement that uses the standards and method described above is usually within 3\% (K.-U. Ludwichowski, personal communication, 2015). Since the dissolution of the vessel material partly depends on the individual vessel, the difference in the silicate molalities of two measurements (e.g. for salinity 10) may be higher.

According to Grasshoff et al. (1999), the accuracy of the measured silicate concentrations also depends on the difference in salinity between the Certipur standard solutions and the DSW samples. Grasshoff et al. (1999) recommend to correct this effect by applying a constant, device-dependent cor- 
Table 3. Dissolved silicate molality of some DSW samples.

\begin{tabular}{lrrrrr}
\hline Vessel & Salinity & $\begin{array}{r}\text { Storage } \\
\text { time in years }\end{array}$ & $\begin{array}{r}\text { Silicate in } \\
\mu \mathrm{mol} \mathrm{kg}^{-1}\end{array}$ & $\begin{array}{r}\text { Uncertainty in } \\
\mu \mathrm{mol} \mathrm{kg} \mathrm{kg}^{-1}\end{array}$ & Batch \\
\hline 1 & 5 & 4.1 & 36.1 & 5.4 & $\mathrm{P} 154$ \\
1 & 10 & 4.7 & 43.2 & 7.2 & $\mathrm{P} 153$ \\
2 & 10 & 4.7 & 48.5 & & $\mathrm{P} 153$ \\
1 & 15 & 4.1 & 37.9 & 5.6 & $\mathrm{P} 154$ \\
1 & 20 & 4.1 & 41.4 & 4.0 & $\mathrm{P} 154$ \\
2 & 20 & 4.1 & 39.5 & & $\mathrm{P} 154$ \\
1 & 25 & 4.1 & 39.7 & 4.0 & $\mathrm{P} 154$ \\
1 & 30 & 4.7 & 57.6 & 6.0 & $\mathrm{P} 153$ \\
2 & 30 & 4.7 & 59.9 & & $\mathrm{P} 153$ \\
- & 35 & 4.7 & $61.3^{*}$ & $6.2^{*}$ & $\mathrm{P} 153$ \\
\hline
\end{tabular}

* Estimated based on silicate molalities for salinities of 10 and 30 .

rection factor derived from calibration measurements. The resulting correction increases linearly based on the salinity difference between the sample (higher salinity) and the standard (lower salinity). For measurements of samples with a salinity of greater than 30 , the correction is smaller than $3 \%$. Assuming a correction due to the salinity effect of $3 \%$ at a salinity difference of 6 and a linear increase thereof, the correction increases to $10 \%$ at a salinity of 15 and to $16 \%$ at a salinity of 5 . We considered this by including the effect in the uncertainty and estimated the uncertainty in silicate molalities to be dominated by the batch homogeneity for salinities above 20; for salinities lower than 20 we estimated the uncertainty to be dominated by the correction due to the salinity. Values of the estimated uncertainty in silicate molality are given in Table 3.

\subsubsection{Density correction to initial silicate content}

Since the density measurements obtained from seawater samples were performed before the silicate molality measurements, the storage time and the silicate molality were different at that time.

Uchida et al. (2011) estimated the relation between the silicate molality $b$ and the storage time $t$ in the vessels to be linear. The silicate-storage time relation of the seawater samples used in the density measurements is therefore estimated based on the initial silicate molality $b_{0}$ (of Uchida et al.) and the measurements of the silicate molality $b_{1}$ (given in Table 3 ) at storage time $t_{1}$ given by

$b=b_{0}+\frac{b_{1}-b_{0}}{t_{1}}$.

The initial silicate molality of the DSW samples that have a salinity of less than 35 is derived from $b_{0}=S_{\mathrm{P}}$. $b_{0}\left(S_{\mathrm{P}}=35\right) / 35$, where the water added to the SSW is assumed to be free of silicate.

The borosilicate vessels used to store the seawater samples are assumed to consist of $w_{\mathrm{SiO}_{2}}=80 \%$ (in weight) sil- ica similar to Duran (DURAN Group GmbH, 2009) or Pyrex (Corning Inc., 2014) borosilicate glass. The dissolution of the silica material is determined using the measurements described above. The dissolution of the remaining $20 \%$ borosilicate glass material, which is $\mathrm{B}_{2} \mathrm{O}_{3}(13 \%)$ but also $\mathrm{Na}_{2} \mathrm{O}$, and $\mathrm{Al}_{2} \mathrm{O}_{3}$, is assumed to be similar to the dissolution of silica (Grambow, 1985). The overall dissolved mass of glass material is therefore given by $\Delta m=M_{\mathrm{SiO}_{2}} / w_{\mathrm{SiO}_{2}} \cdot \Delta n_{\mathrm{SiO}_{2}}$, where $M_{\mathrm{SiO}_{2}}=60.08 \mathrm{~kg} \mathrm{kmol}^{-1}$ is the molar mass of silica and $\Delta n_{\mathrm{SiO}_{2}}$ is the amount-of-substance silica from the glass material that was dissolved into seawater (relative to the initial silicate molality). Additionally, $\Delta n_{\mathrm{SiO}_{2}} \approx\left(b-b_{0}\right) \cdot m$, where $m$ is the seawater mass.

The increase in seawater density due to the dissolution of glass material during storage, $\Delta \rho_{\text {stor }}^{\mathrm{SW}}$, is calculated assuming that the seawater volume remains constant and only the mass increases:

$\Delta \rho_{\text {stor }}^{\mathrm{SW}}=\rho \cdot \frac{M_{\mathrm{SiO}_{2}}}{w_{\mathrm{SiO}_{2}}} \cdot\left(b-b_{0}\right)$,

where $\rho$ is the seawater density. The uncertainty in the density correction due to the dissolution of glass material is estimated using Eq. (7) as a model equation, with Eq. (6) being inserted. Furthermore, the following uncertainties are considered: (i) uncertainty in the silica mass fraction of glass material: $5 \%$, (ii) uncertainty in the initial silicate content $b_{0}$ : $20 \%$, (iii) uncertainty in the measured silicate content $b_{1}$ : as given in Table 3, and (iv) uncertainty in the storage time $t_{1}$ : 15 days.

Some values of the density correction that were applied to the measured seawater densities are shown in Fig. 3. The corrections are about 1 to $3 \mathrm{~g} \mathrm{~m}^{-3}$ and the corresponding estimated uncertainties are $0.4 \mathrm{~g} \mathrm{~m}^{-3}$, which yields an increase in uncertainty of the measured values at atmospheric pressure of up to $8 \%$. The scatter of the correction values for high pressures is higher than that for atmospheric pressure, as density measurements at high pressures take significantly 
longer; as a result, the period between the first and last measurement is longer as well.

\subsection{Air saturation}

Usually, seawater samples used in highly accurate density measurements in laboratories are air-saturated, as any degassing procedure may change the salt composition. For water, the effect of air solubility on density has been measured directly, e.g. by Bignell (1983), by comparing the densities of saturated and desaturated water.

For our density measurements, the seawater samples were taken directly from the vessels delivered by OSIL as shown in Fig. 1a. The vessels were stored in our laboratory at a temperature of approximately $20^{\circ} \mathrm{C}$, at which the seawater equilibrated with the air inside the (closed) vessels. Since the seawater was also pumped into the VTD at this temperature, the air saturation was $100 \%$ at $20^{\circ} \mathrm{C}$. After filling the VTD, the seawater temperature was altered to the measurement temperature. During this time, the saturation changed to undersaturation at temperatures lower than $20^{\circ} \mathrm{C}$ and to oversaturation at temperatures higher than $20^{\circ} \mathrm{C}$, as there was no contact to air during the time of temperature equilibration, which is approximately $15 \mathrm{~min}$. This temperature-dependent aeration is significant compared to the density measurement uncertainty. For consistency of the air saturation, the measured densities have to be corrected to a saturation of either 0 or $100 \%$. Because the density corrections to $100 \%$ are significantly smaller than those to $0 \%$, and because any degassing procedure is problematic, the density values were corrected to $100 \%$ air saturation. Following this procedure, the density-salinity relation was developed with the least loss in accuracy.

The density correction is estimated taking into account the fact that the amount of air molecules remains constant while the liquid temperature changes from $20^{\circ} \mathrm{C}$ to measurement temperature before density measurement. To quantify the density change of seawater by saturation with nitrogen, oxygen and argon in an atmosphere with $100 \%$ humidity, a complex calculation similar to that for water of Harvey et al. (2005) was carried out. For this calculation, the partial molar volumes of nitrogen, oxygen and argon in water were assumed to be equal in seawater. Salinity-dependent solubility data of nitrogen and argon were taken from Hamme and Emmerson (2004) and of oxygen from Garcia and Gordon (1992).

Carbon dioxide exists in three different significant forms in seawater, i.e. as free aqueous molecule, $\mathrm{CO}_{2}$, as bicarbonate ion, $\mathrm{HCO}_{3}{ }^{-}$, and as carbonate ion, $\mathrm{CO}_{3}{ }^{2-}$, the sum of all being called dissolved inorganic carbon (DIC). The DIC concentration as well as that of each species depends on salinity, temperature as well as $\mathrm{CO}_{2}$ partial pressure, if the seawater is in contact with the atmosphere (as described by Henry's law for $\mathrm{CO}_{2}$ ). If the air is humid, the $\mathrm{CO}_{2}$ partial pressure changes with temperature due to the water vapour pressure, whereby $\mathrm{CO}_{2}$ is released from (for temperature increase) or absorbed into seawater (for temperature decrease). Since this affects the $\mathrm{HCO}_{3}^{-}$and $\mathrm{CO}_{3}^{2-}$ concentration, the absolute salinity and thus the density are affected by temperature changes. For standard seawater with a salinity of 35 exposed to air with $100 \%$ humidity, DIC is $\approx 2190 \mu \mathrm{mol} \mathrm{kg}-1$ for $0^{\circ} \mathrm{C}, \approx 2050 \mu \mathrm{mol} \mathrm{kg}^{-1}$ for $20^{\circ} \mathrm{C}$, and $\approx 1870 \mu \mathrm{mol} \mathrm{kg}^{-1}$ for $40^{\circ} \mathrm{C}{ }^{4}$, which, starting from $20^{\circ} \mathrm{C}$, results in density changes of $+1.7 \mathrm{~g} \mathrm{~m}^{-3}$ for $0^{\circ} \mathrm{C}$ and $-2.2 \mathrm{~g} \mathrm{~m}^{-3}$ for $40^{\circ} \mathrm{C}$. A removal of all DIC results in a density change of up to $30 \mathrm{~g} \mathrm{~m}^{-35}$. Since standard seawater is equilibrated with air at $\approx 20^{\circ} \mathrm{C}$ for at least 4 weeks during its preparation (Bacon et al., 2007) and the samples used in the substitution measurements had also been stored at $\approx 20^{\circ} \mathrm{C}$, before they were filled into the densimeter, where their temperature was altered, the DIC was conserved and no correction is necessary. By contrast, if seawater is exposed to the atmosphere during a density measurement, as for example in a hydrostatic weighing densimeter, a density correction may be necessary for temperatures different from $20^{\circ} \mathrm{C}$.

The complex calculation showed that the different gas solubilities in water and seawater are negligible in terms of density, as the deviation between the calculated density change of seawater and that of water (of Harvey et al., 2005) is around $0.1 \mathrm{~g} \mathrm{~m}^{-3}$. Furthermore, it was found that it is sufficient to consider only the nitrogen solubility to calculate the density correction that is approximated by

$$
\begin{aligned}
\Delta \rho_{\mathrm{aer}}^{\mathrm{SW}}= & \left(1-\frac{n_{\mathrm{N}_{2}}\left(100 \%, 20^{\circ} \mathrm{C}\right)}{n_{\mathrm{N}_{2}}(100 \%, T)}\right) \\
& \cdot \Delta \rho_{\mathrm{a}}^{\mathrm{H}_{2} \mathrm{O}}(100 \%, T),
\end{aligned}
$$

where $n_{\mathrm{N}_{2}}\left(100 \%, 20^{\circ} \mathrm{C}\right)$ and $n_{\mathrm{N}_{2}}(100 \%, T)$ are the dissolved nitrogen amounts of a substance at $100 \%$ saturation at $20^{\circ} \mathrm{C}$ and at measurement temperature as well as $\Delta \rho_{\mathrm{a}}^{\mathrm{H}_{2} \mathrm{O}}$ $(100 \%, T)$ being the corresponding density effect, whose calculation is described in Appendix A.

At measurement temperatures higher than $20^{\circ} \mathrm{C}$, the seawater is oversaturated during density measurement, as it was saturated at $20^{\circ} \mathrm{C}$ before filling. It is assumed that the nucleation of microbubbles due to the oversaturation takes significantly longer than the time of temperature stabilization and

\footnotetext{
${ }^{4}$ DIC was calculated using the $\mathrm{CO}_{2}$ calc software developed by Robbins et al. (2010) with the carbonate constants given by Millero (2010) that are also valid for low salinities, the acidity constant of hydrogen sulfate given by Dickson (1990), the boron to chlorinity ratio given by Lee et al. (2010) and the total $\mathrm{pH}$ scale. In the calculations, the total alkalinity was $2300 \mu \mathrm{mol} \mathrm{kg}^{-1}$ (IOC et al., 2010), which is constant for $\mathrm{CO}_{2}$ exchange (Zeebe and Wolf-Gladrow, 2001), and the $\mathrm{CO}_{2}$ molar fraction was $400 \mathrm{ppm}$.

${ }^{5}$ The density change was calculated using $\Delta \rho / \Delta \mathrm{DIC}=$ $0.0120 \mathrm{~g} \mathrm{~m}^{-3} /(\mu \mathrm{mol} \mathrm{kg}-1)$ (Song et al., 2005). Since Bradshaw (1973) found $0.0110 \mathrm{~g} \mathrm{~m}^{-3} /\left(\mu \mathrm{mol} \mathrm{kg}^{-1}\right)$ and Ohsumi et al. (1992) found $0.0128 \mathrm{~g} \mathrm{~m}^{-3} /\left(\mu \mathrm{mol} \mathrm{kg}^{-1}\right)$, the uncertainty in $\Delta \rho / \Delta$ DIC may be $20 \%$.
} 

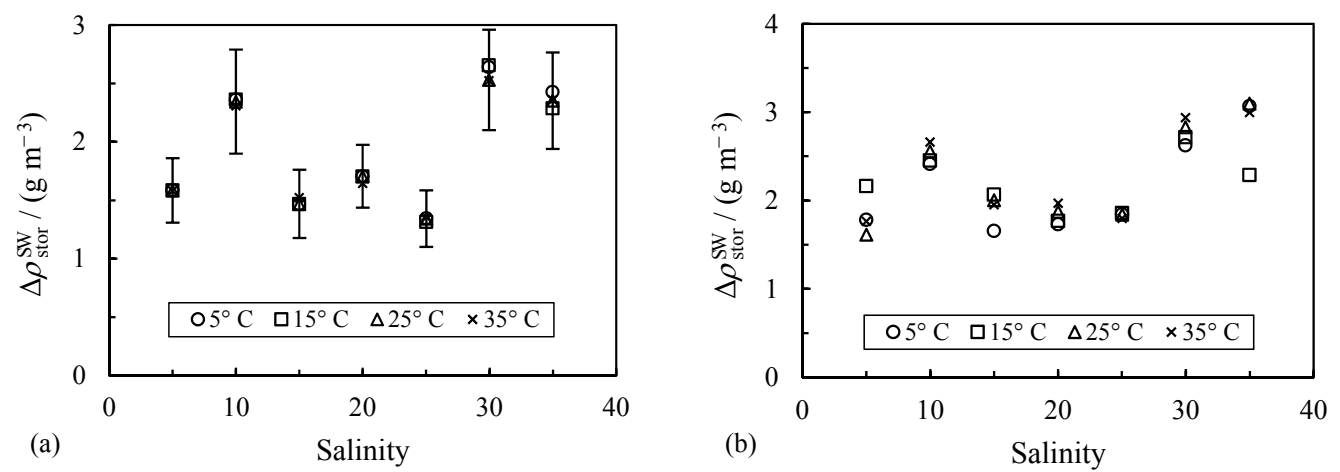

Figure 3. Seawater density increase $\Delta \rho_{\text {stor }}^{\mathrm{SW}}$ caused by dissolution of glass material during storage. Some calculated values of samples used for density measurements (a) at atmospheric pressure and (b) at high pressures. Uncertainty bars in (a) are examples that indicate some uncertainties assigned to values at $25^{\circ} \mathrm{C}$.

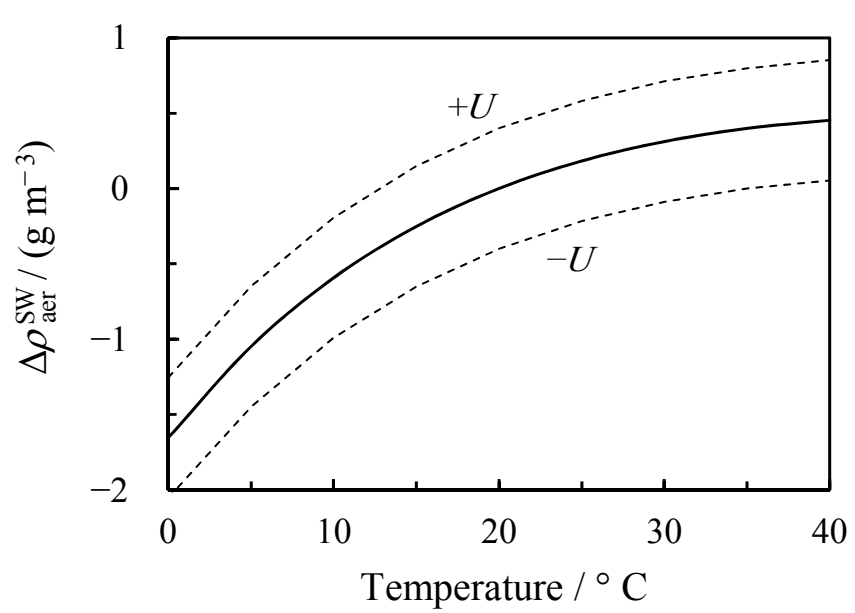

Figure 4. Density correction due to air saturation correction based on $100 \%$ saturation at $20^{\circ} \mathrm{C}$. $U$ - estimated uncertainty.

density measurement, which is always less than $30 \mathrm{~min}$. The density effect caused by oversaturation is therefore assumed to be proportionally equal to that up to saturation. The calculated density correction and the corresponding estimated uncertainty, which is $0.4 \mathrm{~g} \mathrm{~m}^{-3}$, are illustrated in Fig. 4. The density correction is significant at temperatures less than $15^{\circ} \mathrm{C}$ compared to the measurement uncertainty of $2 \mathrm{~g} \mathrm{~m}^{-3}$, as the gas solubility is significantly higher at low temperatures.

Based on a measured substitution density, $\rho_{\text {subs }}^{\mathrm{SW}}$, that has been corrected to the uniform isotopic water and chemical compositions and to $100 \%$ air saturation, a seawater density, $\rho^{\mathrm{SW}}$, was calculated by

$$
\rho^{\mathrm{SW}}=\rho_{\text {subs }}^{\mathrm{SW}}-\Delta \rho_{\text {prep }}^{\mathrm{SW}}+\Delta \rho_{\text {iso }}^{\mathrm{SW}}-\Delta \rho_{\text {stor }}^{\mathrm{SW}}+\Delta \rho_{\mathrm{aer}}^{\mathrm{SW}}+\Delta \rho_{\mathrm{tar}}^{\mathrm{SW}},
$$

where $\Delta \rho_{\mathrm{tar}}^{\mathrm{SW}}$ is a density correction to integer salinities introduced for practicability.

\section{Density-salinity relation}

In this section, the development of the density-salinity relation is described. Although this relation should be used to determine the salinity by means of density, it was set up as a density function of salinity, temperature, and (absolute) pressure, i.e. $\rho=f(S, T, p)$, as doing so allows the data to be approximated more precisely. As a result, the salinity has to be calculated using inverse methods. Since the relation was developed relative to the water density for higher accuracy, the salinity range from 0 to 5 is included by adding the values of pure water. To make use of this relation even beyond this range and the ranges measured, the uncertainty was estimated for somewhat wider ranges in the absence of measurement data. The relation accuracy was verified by means of a new method that verifies the uncertainty in predicted results locally using the measurement results, taking into account the correlation between the two. This is particularly advantageous for empirical fit equations, as these are not physical laws and are therefore not inherently consistent, i.e. they are not independent of the measurement results themselves.

\subsection{Physical model}

The density of air-saturated seawater is modelled based on degassed water, whose density is given by $\rho_{0}^{\mathrm{H}_{2} \mathrm{O}}$. Salt that has a relative composition similar to that dissolved in standard seawater is added to the degassed water. The salt content is given implicitly by the salinity. The density of the degassed water changes after the salt is added by $\Delta \rho_{0}^{\mathrm{SW}}$. In addition, air with a defined composition is absorbed, as a result of which the density changes by $\Delta \rho_{\mathrm{a}}^{\mathrm{SW}}$. The density of air-saturated seawater, $\rho^{\mathrm{SW}}$, is thus given by

$\rho^{\mathrm{SW}}=\rho_{0}^{\mathrm{H}_{2} \mathrm{O}}+\Delta \rho_{0}^{\mathrm{SW}}+\Delta \rho_{\mathrm{a}}^{\mathrm{SW}}$,

where $\rho_{0}^{\mathrm{H}_{2} \mathrm{O}}$ is the density of degassed water, $\Delta \rho_{0}^{\mathrm{SW}}$ is the density change due to dissolved salt, and $\Delta \rho_{\mathrm{a}}^{\mathrm{SW}}$ is the density change due to absorbed air. The density change due to 
dissolved salt and absorbed air may be summarized by $\Delta \rho^{\mathrm{SW}}$ and may also be called relative density of air-saturated seawater, as the seawater density was measured relative to water in the substitution measurements.

If the salt is added at the atmospheric pressure $p_{0}$, the water density changes by $\Delta \rho_{0}^{\mathrm{SW}}\left(p_{0}\right)$. If the salt is added at the pressure $p \neq p_{0}$, the water density changes by $\Delta \rho_{0}^{\mathrm{SW}}(p)$. If the difference between the two changes is $\Delta \Delta \rho_{0}^{\mathrm{SW}}\left(p-p_{0}\right)$, then the density change due to dissolved salt at any pressure is given by

$\Delta \rho_{0}^{\mathrm{SW}}=\Delta \rho_{0}^{\mathrm{SW}}\left(p_{0}\right)+\Delta \Delta \rho_{0}^{\mathrm{SW}}\left(p-p_{0}\right)$,

where $\Delta \rho_{0}^{\mathrm{SW}}\left(p_{0}\right)$ is the density change due to dissolved salt at the atmospheric pressure $p_{0}$ and $\Delta \Delta \rho_{0}^{\mathrm{SW}}\left(p-p_{0}\right)$ is the difference between the density changes at the pressure $p$ and at the atmospheric pressure $p_{0}$.

The solubility of gases in liquids is described well at infinite dilution and low pressure by means of Henry's law, according to which the number of absorbed gas molecules is proportional to the gas pressure above the liquid. However, since there is no reservoir for additional gas at high pressure, only the air absorption at the gas pressure $p_{0}$ is taken into account for modelling. In addition, it is assumed that the absorbed air is incompressible. In the model, the density change due to absorbed air is therefore not treated as a function of pressure, i.e. $\Delta \rho_{\mathrm{a}}^{\mathrm{SW}} \neq f(p)$.

The solubility of air in seawater depends on salinity (Hamme and Emmerson, 2004; Garcia and Gordon, 1992). The comparison of the $\mathrm{N}_{2}, \mathrm{O}_{2}$, and Ar solubilities in water and seawater showed that the resulting density change in both liquids is approximately equal. In the model, the density change due to absorbed air is therefore not a function of salinity, i.e. $\Delta \rho_{\mathrm{a}}^{\mathrm{SW}}=\Delta \rho_{\mathrm{a}}^{\mathrm{H}_{2} \mathrm{O}} \neq f(S)$.

\subsection{Fitting of $\Delta \rho_{0}^{\mathrm{SW}}\left(p_{0}\right)$}

The values of the seawater density for atmospheric pressure, $\rho^{\mathrm{SW}}$, which were obtained from the measurements and corrected to the uniform conditions, were broken down according to $\mathrm{Eq}_{\text {. }}(10)$ into the corresponding values of the water density, $\rho_{0} \mathrm{H}_{2} \mathrm{O}$, and the values yielded by the density change due to dissolved salt and absorbed air (or relative density of air-saturated seawater), $\Delta \rho^{\mathrm{SW}}$. For this purpose, the water density was calculated using the equation of state developed by Wagner and Pruß (2002), by means of which the water reference density for the substitution measurements was calculated as well. Therefore, the uncertainty in the relative density is up to $20 \%$ lower than that in the absolute density.

The values of the relative density of air-saturated seawater $\Delta \rho^{\mathrm{SW}}$ were broken down into the resulting values of the density change due to dissolved salt, $\Delta \rho_{0}^{\mathrm{SW}}\left(p_{0}\right)$, and the corresponding values of density change due to absorbed air, $\Delta \rho_{\mathrm{a}}^{\mathrm{SW}}$. For this purpose, the values of $\Delta \rho_{\mathrm{a}}^{\mathrm{SW}}$ were calculated using the equation of Harvey et al. (2005), which is valid for the absorption of air into water at $p_{0}=101325 \mathrm{~Pa}$, but were adopted for the absorption of air into seawater according to the physical model described above:

$$
\begin{aligned}
\frac{\Delta \rho_{\mathrm{a}}^{\mathrm{SW}}(T)}{\mathrm{g} \mathrm{m}^{-3}}= & 0.103-2.371 \times 10^{5} \cdot\left(\frac{T}{{ }^{\circ} \mathrm{C}}+75\right)^{-2.5} \\
& +1.82 \times 10^{-7} \cdot\left(\frac{T}{{ }^{\circ} \mathrm{C}}+75\right)^{3},
\end{aligned}
$$

where the model air composition is $78.1 \% \mathrm{~N}_{2}, 20.9 \% \mathrm{O}_{2}$, $0.9 \% \mathrm{Ar}$, and $0.4 \% \circ \mathrm{CO}_{2}$. This equation is also given in Appendix A, but is repeated here for clarity. Free aqueous $\mathrm{CO}_{2}$ contributes less than $0.2 \mathrm{~g} \mathrm{~m}^{-3}$ to $\Delta \rho_{\mathrm{a}}^{\mathrm{SW}}$ and is therefore negligible.

The values of the relative density of degassed seawater, $\Delta \rho_{0}^{\mathrm{SW}}\left(p_{0}\right)$, were used to fit the coefficients $a_{i, j}$ of the following empirical equation:

$\Delta \rho_{0}\left(p_{0}\right)=\Delta \rho_{0}^{\mathrm{o}} \cdot \sigma \cdot \sum_{i=0}^{5} \sum_{j=0}^{5-i} a_{i, j} \cdot \tau^{i} \cdot \sigma^{j}$,

where $\Delta \rho_{0}^{\mathrm{o}}=30 \mathrm{~kg} \mathrm{~m}^{-3}, \tau=T / T^{\mathrm{o}}$ is the reduced temperature with $T$ being the temperature in $\mathrm{K}$ and $T^{\circ}=288.15 \mathrm{~K}$, and $\sigma=S / S^{\circ}$ is the reduced salinity with $S$ being the salinity and $S^{\mathrm{o}}=35$. The values of $\Delta \rho_{0}^{\mathrm{o}}, T^{\mathrm{o}}$, and $S^{\mathrm{o}}$ (as well as $\Delta \Delta \rho_{0}^{0}$ and $\pi^{\circ}$ below) were chosen for practical handling of the fit coefficient values and do not have a physical meaning.

The linear fit coefficients $a_{i, j}$ were determined by uncertainty-weighted least squares fitting within the Monte Carlo based approach described in Appendix B. The fit coefficients were initially averaged from up to $n=1500$ runs, where no longer significant effects on calculated values or uncertainties thereof were found. Finally, the coefficients were averaged from $n=15000$ runs to be certain. The fitting yielded the values of $a_{i, j}$ given in Table 4 , which were reduced to the significant number of digits.

The residuals of the fit using the coefficients given in Table 4 are illustrated in Fig. 5, where they are compared with the density-salinity relation uncertainty, $U$, whose determination is described below. The residual standard deviation is $1.1 \mathrm{~g} \mathrm{~m}^{-3}$. No systematic deviation of the residuals depending on salinity or temperature was found.

If the density of air-saturated seawater is calculated using the density-salinity relation, the (fitted) relative seawater density plus the (artificially inserted) density change due to absorbed air is used, i.e. $\Delta \rho^{\mathrm{SW}}=\Delta \rho_{0}^{\mathrm{SW}}+\Delta \rho_{\mathrm{a}}^{\mathrm{SW}}$. However, $\Delta \rho_{\mathrm{a}}^{\mathrm{SW}}$ has practically no statistical influence on the fitting of $\Delta \rho_{0}^{\mathrm{SW}}$, and therefore no statistical influence on $\Delta \rho^{\mathrm{SW}}$. Consequently, if $\Delta \rho^{\mathrm{SW}}$ is calculated, its uncertainty is $U\left(\Delta \rho_{0}^{\mathrm{SW}}\right)$, i.e. that of the degassed seawater density, whereas, if $\Delta \rho_{0}^{\mathrm{SW}}$ is calculated, its uncertainty is $\left[U\left(\Delta \rho_{0}^{\mathrm{SW}}\right)^{2}+U\left(\Delta \rho_{\mathrm{a}}^{\mathrm{SW}}\right)^{2}\right]^{1 / 2}$, i.e. that of the degassed seawater density and that of the density change due to absorbed air. 
Table 4. Values of the coefficients $a_{i, j}$ of Eq. (13).

\begin{tabular}{rrr|rrr|rrr}
\hline$i$ & $j$ & Value & $i$ & $j$ & Value & $i$ & $j$ & Value \\
\hline 0 & 0 & $2.65627133 \times 10^{+2}$ & 1 & 1 & $8.0658117 \times 10^{+1}$ & 2 & 3 & $-4.1658 \times 10^{-1}$ \\
0 & 1 & $-2.272462 \times 10^{+1}$ & 1 & 2 & $-8.62107 \times 10^{+0}$ & 3 & 0 & $-1.996354156 \times 10^{+3}$ \\
0 & 2 & $3.17932 \times 10^{+0}$ & 1 & 3 & $6.3513 \times 10^{-1}$ & 3 & 1 & $6.332479 \times 10^{+1}$ \\
0 & 3 & $-2.78076 \times 10^{-1}$ & 1 & 4 & $6.7777 \times 10^{-2}$ & 3 & 2 & $-2.182108 \times 10^{+0}$ \\
0 & 4 & $-3.7051 \times 10^{-2}$ & 2 & 0 & $2.182680018 \times 10^{+3}$ & 4 & 0 & $9.16301655 \times 10^{+2}$ \\
0 & 5 & $-6.648 \times 10^{-3}$ & 2 & 1 & $-1.0724787 \times 10^{+2}$ & 4 & 1 & $-1.4043174 \times 10^{+1}$ \\
1 & 0 & $-1.198640497 \times 10^{+3}$ & 2 & 2 & $7.686316 \times 10^{+0}$ & 5 & 0 & $-1.68713114 \times 10^{+2}$ \\
\hline
\end{tabular}

The uncertainty in $\Delta \rho_{0}^{\mathrm{SW}}\left(p_{0}\right)$ was determined and verified using the approach described in Appendix B. The calculated uncertainty is at least $\left(0.7 \mathrm{~g} \mathrm{~m}^{-3}\right)$ at a salinity of 15 and at $25^{\circ} \mathrm{C}$, and increases as expected at higher salinities, as well as at lower and higher temperatures (up to $1.2 \mathrm{~g} \mathrm{~m}^{-3}$ ). The subsequent uncertainty verification yielded four inconsistent densities whose residuals were higher than their corresponding uncertainties. The uncertainty was therefore increased to $2 \mathrm{~g} \mathrm{~m}^{-3}$ in the entire measurement region of salinities up to 35 and temperatures from 5 to $35^{\circ} \mathrm{C}$.

Since the density-salinity relation may be used for calculations in a wider region, e.g. salinities up to 40 and temperatures from 0 to $40^{\circ} \mathrm{C}$, we also estimated the uncertainty in $\Delta \rho_{0}^{\mathrm{SW}}\left(p_{0}\right)$ for this region in the absence of measurement data. The density uncertainty in the wider (extrapolation) region was also calculated using the approach described in Appendix $\mathrm{B}$, whereby the possible variation of the fit polynomial outside the measured salinity and temperature region is taken into account. The uncertainties resulting from this calculation are shown in Fig. 6a together with the uncertainty of the measurement region. For practicability, the highest uncertainty in a particular region was assigned. The uncertainties in the extrapolation region are at least twice as much as in the measurement region.

To calculate salinity using relative density and temperature values by means of the density-salinity relation, the uncertainty in salinity was also determined in the measurement and extrapolation region. The salinity uncertainty was calculated by multiplying the density uncertainty by the partial derivative of salinity by density, i.e. $U(S)=U(\Delta \rho \mathrm{SW}) \cdot \partial S / \partial \rho$. The uncertainties resulting from this calculation are shown in Fig. 6b. A salinity determined by means of a calculation using the relation has an uncertainty of $3 \times 10^{-3}$. If measurement values are used for calculation, their uncertainty has to be considered.

Since the mathematical formulation of the density-salinity relation is empirical and does not contain any theoretical boundary conditions for infinite dilution, as for example implemented in TEOS-10, the question arises whether the relation correctly predicts the density for very low salinities. Additionally, no uncertainty verification in the extrapolation region is possible using the fitting data set. There-

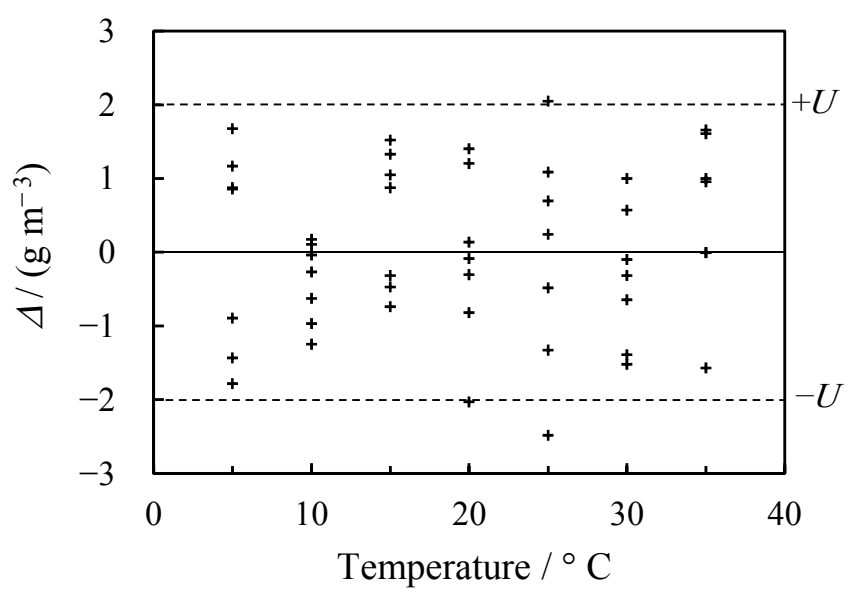

Figure 5. Residuals $\Delta$ (measured minus the predicted values) resulting from the fit of $\Delta \rho_{0}^{\mathrm{SW}}\left(p_{0}\right) . U$ - uncertainty in the densitysalinity relation.

fore, additional substitution density measurements were conducted: The density of diluted standard seawater with salinity 2 was measured at some temperatures and the density of some samples of the seawater used for determination of the density-salinity relation was measured at $1{ }^{\circ} \mathrm{C}$. The seawater with salinity 2 was prepared like the seawater with salinities from 5 to 30 . Unfortunately, the precision in the salinity-2-calibration was lower, so that the uncertainty in salinity is 0.0028 corresponding to an uncertainty in density of $2.2 \mathrm{~g} \mathrm{~m}^{-3}$. The density results were corrected to the uniform isotopic water and the chemical salt compositions as well as air saturation as described in Sect. 3. The density deviations of the corrected results from the predicted values of the density-salinity relation are shown in Fig. 7. In both cases, the deviations are well within the uncertainty in the density-salinity relation. For the measurements of seawater with salinity 2 , even if the uncertainty in salinity is treated as an offset to all deviations, the deviation is within its uncertainty. No inconsistencies are caused by the non-compliance with theoretical boundary conditions for very low salinities and atmospheric pressure. 

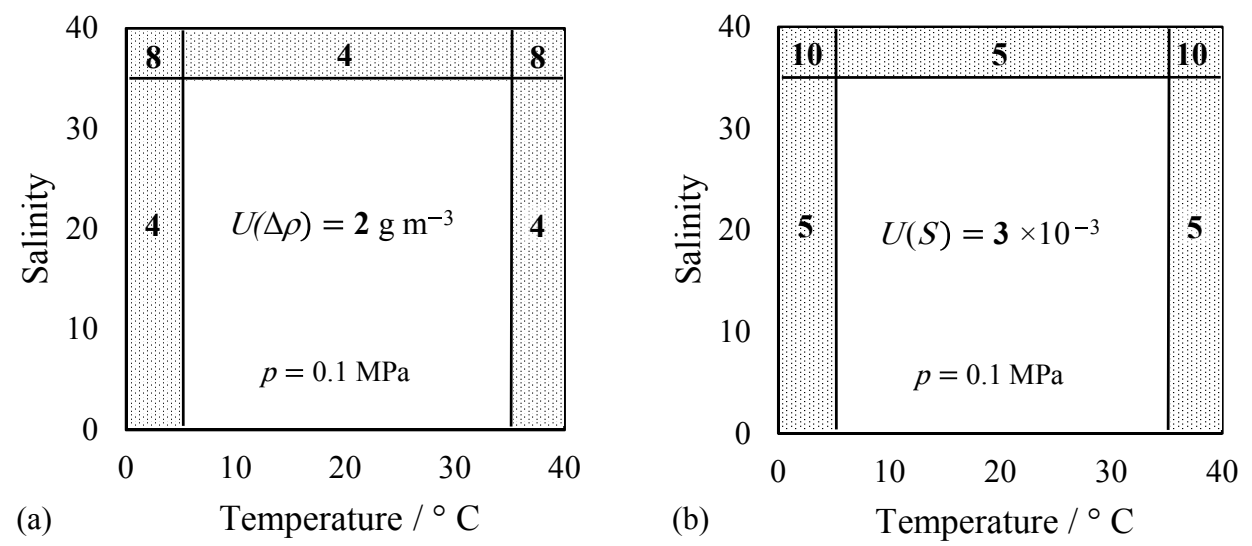

Figure 6. Uncertainty in the density-salinity relation at $101325 \mathrm{~Pa}$. (a) Uncertainty in the relative density of air-saturated seawater, $U\left(\Delta \rho^{\mathrm{SW}}\right)$, that results from a calculation using salinity and temperature values. (b) Uncertainty in salinity, $U(S)$, that results from an inverse calculation using the relative density of air-saturated seawater and temperature values. The white area indicates the measurement region equal to that of the data set used for fitting. The grey area indicates the extrapolation region.
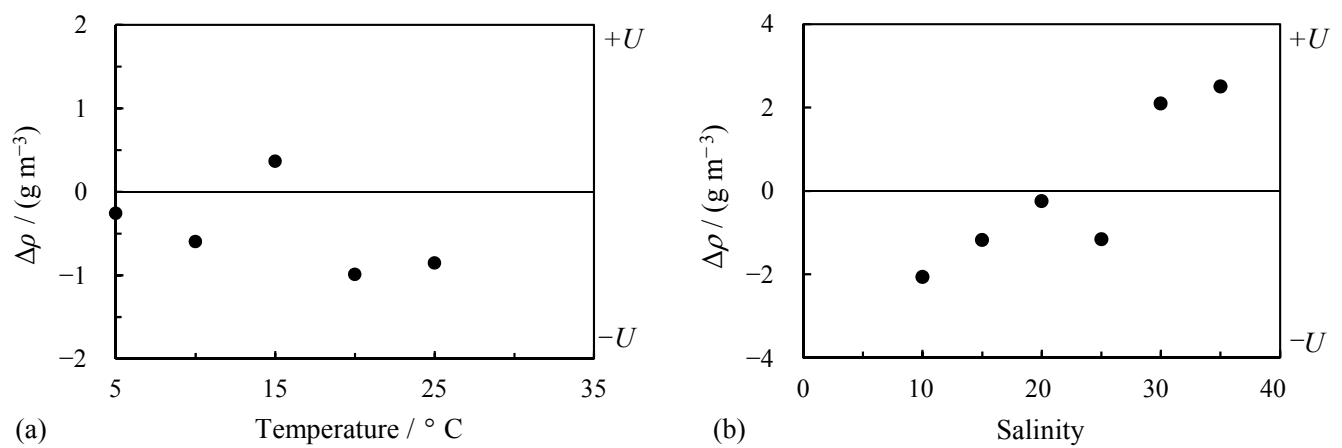

Figure 7. Deviation of measured from predicted seawater densities $\Delta \rho$. (a) In the interpolation region at salinity 2 and (b) in the extrapolation region at $1^{\circ} \mathrm{C}$ and atmospheric pressure, respectively. $U$ - uncertainty in the density-salinity relation.

\subsection{Fitting of $\Delta \Delta \rho_{0}^{\mathrm{SW}}\left(p-p_{0}\right)$}

The values of the seawater density for high pressures, $\rho^{\mathrm{SW}}$, were broken down according to Eq. (10) into corresponding values of the water density, $\rho_{0}^{\mathrm{H}_{2} \mathrm{O}}$, and the values yielded by the density change due to dissolved salt and absorbed air (or relative density of air-saturated seawater), $\Delta \rho^{\mathrm{SW}}$. Since the water density was calculated analogously to the atmospheric pressure densities, the uncertainty in the relative density is up to $50 \%$ lower than that in the absolute density for pressures up to $10 \mathrm{MPa}$ and up to $80 \%$ lower for up to $65 \mathrm{MPa}$.

The values of the relative density of air-saturated seawater, $\Delta \rho^{\mathrm{SW}}$, were broken down into the values yielded by the density change due to dissolved salt, $\Delta \rho_{0}^{\mathrm{SW}}$, and the corresponding values of the density change due to absorbed air, $\Delta \rho_{\mathrm{a}}^{\mathrm{SW}}$. For this purpose, the values of $\Delta \rho_{\mathrm{a}}^{\mathrm{SW}}$ were calculated analogously to the atmospheric pressure densities using Eq. (12).

The values of the density change due to dissolved salt, $\Delta \rho_{0}^{\mathrm{SW}}$, were further broken down according to Eq. (11) into the values of the density change due to dissolved salt at the atmospheric pressure $p_{0}=101325 \mathrm{~Pa}, \Delta \rho_{0}^{\mathrm{SW}}\left(p_{0}\right)$, and the difference between the density change at (high) pressure $p$ and that at the pressure $p_{0}, \Delta \Delta \rho_{0}^{\mathrm{SW}}\left(p-p_{0}\right)$. The relative density values for atmospheric pressure that had been used to fit the coefficients of Eq. (13), were used for this purpose.

The resulting values of the density difference $\Delta \Delta \rho_{0}^{\mathrm{SW}}\left(p-p_{0}\right)$ were used to fit the coefficients $b_{i, j, k}$ of the following empirical equation:

$$
\begin{gathered}
\Delta \Delta \rho_{0}^{\mathrm{SW}}\left(p-p_{0}\right)=\Delta \Delta \rho_{0}^{\mathrm{o}} \cdot \sigma \cdot \pi \cdot \sum_{i=0}^{4} \sum_{j=0}^{4-i} \sum_{k=0}^{4-i-j} b_{i, j, k} \\
\cdot \tau^{i} \cdot \sigma^{j} \cdot \pi^{k},
\end{gathered}
$$

where $\Delta \Delta \rho_{0}^{\mathrm{o}}=2 \mathrm{~kg} \mathrm{~m}^{-3}, \pi=\left(p / p^{\mathrm{o}}-1\right) / \pi^{\mathrm{o}}$ with $p$ being the pressure in $\mathrm{MPa}, p^{\mathrm{o}}=p_{0}=0.101325 \mathrm{MPa}$, and $\pi^{\mathrm{o}}=1000$. Due to the formulation of the dimensionless pressure $\pi, \Delta \Delta \rho_{0}$ is exactly zero at $p_{0}$, thereby ensuring the high accuracy of the density at atmospheric pressure $\Delta \rho_{0}\left(p_{0}\right)$.

The linear fit coefficients $b_{i, j, k}$ were determined analogously to the fit coefficients $a_{i, j}$ using the approach de- 


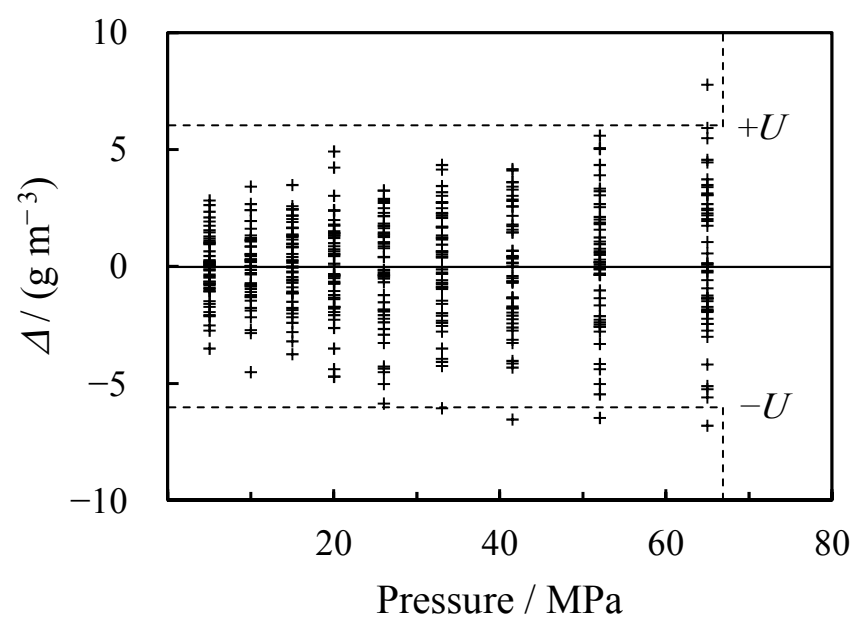

Figure 8. Residuals $\Delta$ (measured minus predicted values) yielded by the fit of $\Delta \Delta \rho_{0}^{\mathrm{SW}}\left(p-p_{0}\right)$. $U-$ uncertainty in the densitysalinity relation for high pressures.

scribed in Appendix B. The fitting yielded the values of $b_{i, j, k}$ given in Table 5, which were reduced to the significant number of digits. The residuals of the fit using the coefficients given in Table 5 are illustrated in Fig. 8. The uncertainty of the measured relative densities underlying the fit range from 6 up to $14 \mathrm{~g} \mathrm{~m}^{-3}$ for salinities from 5 up to 35 and were estimated conservatively. The fit standard deviation of $2.3 \mathrm{~g} \mathrm{~m}^{-3}$, which is $5 \mathrm{~g} \mathrm{~m}^{-3}$ for a probability of $95.45 \%$, and the fact that no systematic deviation of the residuals depending on salinity, temperature, or pressure is found suggest that the uncertainty in the measured relative densities may have been overestimated, i.e. their accuracy may have been underestimated. The density uncertainty in the measurement region was determined using the approach described in Appendix $\mathrm{B}$ and yielded an uncertainty of $6 \mathrm{~g} \mathrm{~m}^{-3}$, thereby supporting the suggestion. The uncertainty of $6 \mathrm{~g} \mathrm{~m}^{-3}$ was therefore adopted for the measurement region. One residual for $41.5 \mathrm{MPa}$, one for $52 \mathrm{MPa}$ and two for $65 \mathrm{MPa}$, of 49 , respectively, exceed this uncertainty significantly.

The data set for fitting $\Delta \Delta \rho_{0}^{\mathrm{SW}}\left(p-p_{0}\right)$ comprises pressures up to $65 \mathrm{MPa}$. Since the density-salinity relation may be used for calculations over a wider range, e.g. pressures up to $100 \mathrm{MPa}$, the uncertainty in this range was estimated in the absence of measurement data. Summarized results of this calculation are shown in Fig. 9a and c together with the results of the measurement region. For practicability, the highest uncertainty in a particular region was assigned. The uncertainties in the extrapolation region are at least twice as much as in the measurement region. For calculating salinity using relative density, temperature, and pressure values by means of the density-salinity relation, the uncertainty in salinity was also determined in the measurement and extrapolation region. The salinity uncertainty was calculated by multiplying the density uncertainty by the partial derivative of salinity by density, i.e. $U(S)=U\left(\Delta \rho^{\mathrm{SW}}\right) \cdot \partial S / \partial \rho$. The uncertainties yielded by this calculation are shown in Fig. $9 \mathrm{~b}$ and $\mathrm{d}$. A salinity determined by means of a calculation using the relation in the measurement region has an uncertainty of $8 \times 10^{-3}$. If measurement values are used for calculation, their uncertainty has to be included.

As pointed out above, the mathematical formulation of the density-salinity relation is empirical and does not contain any theoretical boundary conditions for infinite dilution. This is also an issue for the density at high pressures, as here the measurement uncertainty in density is higher, thereby causing more variability in the shape of the relation for very low salinities. Therefore, additional measurements were conducted on diluted standard seawater with salinity 2 for some temperatures. The samples used were obtained from the same seawater as described above in Sect. 4.2; the corrections were similar. The density deviations of the corrected values from predicted values of the density-salinity relation are shown in Fig. 10. The deviations are well within the uncertainty in the relation. No inconsistencies are caused by the non-compliance with theoretical boundary conditions for very low salinities and high pressures.

\section{Comparison with TEOS-10}

The present reference equation of state for thermodynamic properties of seawater is the Thermodynamic Equation of Seawater (TEOS-10) adopted by the Intergovernmental Oceanographic Commission (IOC et al., 2010). TEOS-10 describes the properties of degassed seawater in wide ranges of salinity, temperature, and pressure relative to degassed water with the VSMOW isotopic composition. Relative density values calculated using TEOS- 10 with salinities from 0 to 40 and temperatures from 0 to $40^{\circ} \mathrm{C}$ have estimated uncertainties of $8 \mathrm{~g} \mathrm{~m}^{-3}$ for atmospheric pressure, $17 \mathrm{~g} \mathrm{~m}^{-3}$ up to $10 \mathrm{MPa}$, and $26 \mathrm{~g} \mathrm{~m}^{-3}$ up to $100 \mathrm{MPa}$. To possibly reduce the density uncertainty in these regions, TEOS-10 was compared with the density-salinity relation.

\subsection{Atmospheric pressure}

For atmospheric pressure, the density deviation of TEOS10 from the density-salinity relation is shown in Fig. 11a. TEOS-10 density values are always higher than those of the density-salinity relation. The increase in the deviation with salinity is approximately linear. At salinities higher than 25, the deviation exceeds the estimated uncertainty of $8 \mathrm{~g} \mathrm{~m}^{-3}$ significantly. At salinities smaller than 5, the deviation, although consistent, is unexpectedly high. Salinity 0 , which is pure water, defines the zero-line of TEOS-10 and of the density-salinity relation.

To leave the linear increase in the deviation with salinity seen in Fig. 11a out of consideration, a reduced form is shown in Fig. 11b. Here, $\Delta \rho-\Delta \rho(S=35) \cdot S / 35$ is visual- 
Table 5. Values of the coefficients $b_{i, j, k}$ of Eq. (14).

\begin{tabular}{rrrr|rrrr}
\hline$i$ & $j$ & $k$ & Value & $i$ & $j$ & $k$ & Value \\
\hline 0 & 0 & 0 & $-7.739482 \times 10^{+2}$ & 1 & 0 & 3 & $3.8065 \times 10^{-1}$ \\
0 & 0 & 1 & $7.621224 \times 10^{+1}$ & 1 & 1 & 0 & $2.09786 \times 10^{+0}$ \\
0 & 0 & 2 & $-2.47174 \times 10^{+0}$ & 1 & 1 & 1 & $4.38047 \times 10^{+0}$ \\
0 & 0 & 3 & $-5.109 \times 10^{-1}$ & 1 & 1 & 2 & $-2.5183 \times 10^{-1}$ \\
0 & 0 & 4 & $5.975 \times 10^{-2}$ & 1 & 2 & 0 & $8.72384 \times 10^{+0}$ \\
0 & 1 & 0 & $2.95926 \times 10^{+0}$ & 1 & 2 & 1 & $1.7845 \times 10^{+0}$ \\
0 & 1 & 1 & $-1.98326 \times 10^{+0}$ & 1 & 3 & 0 & $-1.2344 \times 10^{-1}$ \\
0 & 1 & 2 & $5.0082 \times 10^{-1}$ & 2 & 0 & 0 & $-3.72241428 \times 10^{+3}$ \\
0 & 1 & 3 & $-6.353 \times 10^{-2}$ & 2 & 0 & 1 & $1.8587744 \times 10^{+2}$ \\
0 & 2 & 0 & $-4.73032 \times 10^{+0}$ & 2 & 0 & 2 & $-2.80757 \times 10^{+0}$ \\
0 & 2 & 1 & $-1.2834 \times 10^{+0}$ & 2 & 1 & 0 & $-1.147437 \times 10^{+1}$ \\
0 & 2 & 2 & $-7.863 \times 10^{-2}$ & 2 & 1 & 1 & $-2.9345 \times 10^{+0}$ \\
0 & 3 & 0 & $4.9266 \times 10^{-1}$ & 2 & 2 & 0 & $-4.66432 \times 10^{+0}$ \\
0 & 3 & 1 & $-1.9762 \times 10^{-1}$ & 3 & 0 & 0 & $2.2414666 \times 10^{+3}$ \\
0 & 4 & 0 & $-5.466 \times 10^{-2}$ & 3 & 0 & 1 & $-5.56069 \times 10^{+1}$ \\
1 & 0 & 0 & $2.7623136 \times 10^{+3}$ & 3 & 1 & 0 & $6.98502 \times 10^{+0}$ \\
1 & 0 & 1 & $-2.061301 \times 10^{+2}$ & 4 & 0 & 0 & $-5.0878713 \times 10^{-6}$ \\
1 & 0 & 2 & $5.30055 \times 10^{+0}$ & & & & \\
\hline & & & & & \\
\hline
\end{tabular}

ized. It is found that the reduced deviation is always less than $5 \mathrm{~g} \mathrm{~m}^{-3}$.

To find possible causes of the unexpectedly high density deviation, the density data on which TEOS-10 is based were examined, where the uncertainty in salinity was considered negligible. In the $\left(S, T, p_{0}\right)$ region of interest, according to Feistel $(2003,2008)$, TEOS-10 is based on a data set (JPOTS, 1981c, pp. 36-56) that consists of normalized density data of Millero et al. (1976) and of Poisson et al. (1980), where the density data of Millero et al. have a significantly higher precision. For atmospheric pressure, this data set was also used to fit the previous reference equation of state EOS-80 (JPOTS, 1981c), and, therefore, no comparison with EOS-80 was carried out.

Millero et al. (1976) measured the density of diluted and standard seawater of batch P63 using a magnetic float densimeter. The comparison between the normalized densities measured by Millero et al. and TEOS-10 shown in Fig. 12a suggests that TEOS-10 is well fitted to these densities. Furthermore, for salinities less than 30 (compared to for salinities greater than or equal to 30), the deviation is strongly scattered and the salinity value of each deviation value is different. This may be explained by the fact that not all density measurements were carried out in a closed measuring vessel (JPOTS, 1981c, p. 35), thereby avoiding evaporation, which would increase the salinity and density during a measurement. To exclude the impact of the data normalization, a comparison of the original densities of Millero et al. (1976) and the density-salinity relation is shown in Fig. 12b, where the measurements that were carried out in a closed measuring vessel are separated from those that were putatively carried out in an open measuring vessel. The deviations of the closed-vessel measurements (for salinity 30 and 35) are the smallest and scatter the least, whereas the deviations of the open-vessel measurements (for all other salinities) scatter highly. If it is assumed that evaporation occurred during the open-vessel measurements, then the measured densities can be systematically too high (or the assigned salinities too small), which would cause the open-vessel deviations to be too high. Furthermore, a linear fit curve that was developed using the closed-vessel deviations is shown, as it is possible that there is a systematic deviation increasing linearly with salinity besides the evaporation. The smallest open-vessel deviations, which are most likely not significantly affected by evaporation, correlate conspicuously with this fit curve, thereby supporting the possibility of systematic deviation. The open-vessel densities for salinity 40, which are visible as the highest deviations in Fig. 12b, were corrected (using the closed-vessel densities) when the density data of Millero et al. and Poisson et al. were normalized (JPOTS, 1981c, pp. 35 and 58), which is why there are no significant deviations for salinity 40 in Fig. 12a. It should be noted that for calculation of the density deviations given in Fig. 12a and $b$, the temperatures at which Millero et al. made their measurements were converted from the International Practical Temperature Scale 1968 to the International Temperature Scale 1990 (CCT, 1997). To identify plausible causes of the systematic deviation, we thoroughly examined the magnetic flotation method used by Millero et al. for possible issues.

Magnetic float densimeters have the advantage over hydrostatic weighing densimeters that no mechanical coupling by means of a suspension is needed to determine the buoyancy 

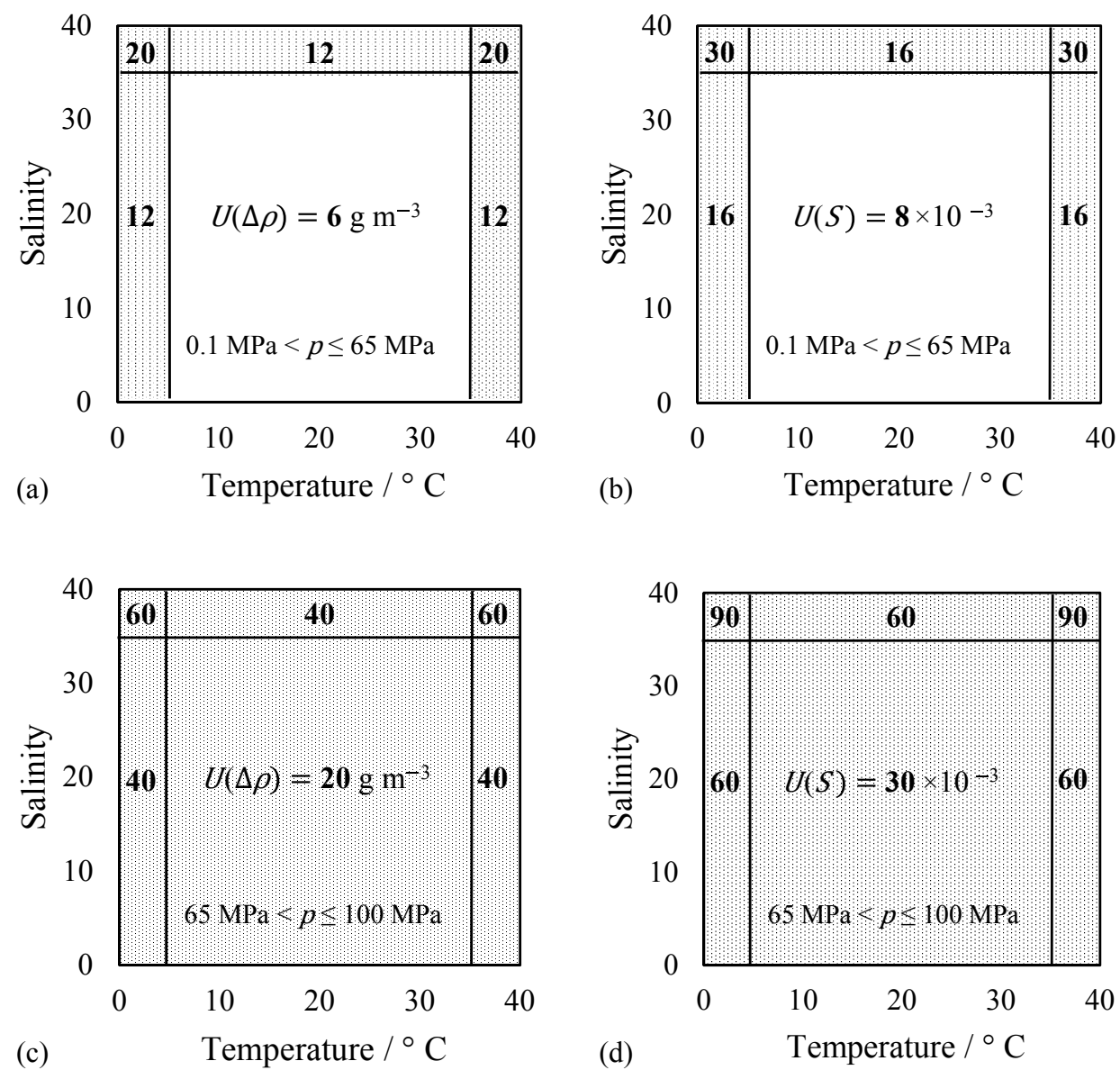

Figure 9. Uncertainty in the density-salinity relation at high pressures. Uncertainty in the relative density of air-saturated seawater, $U\left(\Delta \rho^{\mathrm{SW}}\right)$, that results from a calculation using salinity and temperature values for pressures (a) up to $65 \mathrm{MPa}$ and (c) up to $100 \mathrm{MPa}$. Uncertainty in salinity, $U(S)$, that results from an inverse calculation using the relative density of air-saturated seawater and temperature values for pressures (b) up to $65 \mathrm{MPa}$ and (d) up to $100 \mathrm{MPa}$. The white area indicates the interpolation region equal to that of the data set used for fitting. The grey area indicates the extrapolation region.

force acting on a float (or sinker). Instead, this is achieved with a magnetic coupling by placing a magnet into a float. The float is brought to mechanical equilibrium, i.e. floats in the liquid, by means of a current-carrying coil; here, the current is a measure of the force, and thus of the liquid density. However, for density measurement the characterization of the magnetic coupling is necessary in addition to the determination of the float volume, as in the case of a hydrostatic weighing densimeter.

The densimeter used by Millero et al. for measuring the seawater density consisted of a hollow float in the measuring liquid of a vessel that had a volume of $250 \mathrm{~mL}$, with the coil mounted underneath. The float was made of Pyrex, contained a permanent magnet that was a stirring bar and was therefore probably made of Alnico, and had a volume of $32 \mathrm{~cm}^{-3}$ (Millero, 1967). The float was weighted with platinum weights to adjust its buoyancy. The current that passed through the coil was used to pull the float to the bottom of the measuring vessel. Subsequently, the current intensity was gradually reduced until the float lifted off the bottom. The equilibrium current determined in this way, which was assumed to define the state of floating, was a measure of the liquid density.

Bignell (2006) discussed various methods for determining the buoyancy force in magnetic float densimeters. For the design of the magnetic coupling system, the magnetic force exerted on a permanent magnet by a current-carrying, circular coil (without a metal core) was given by

$$
F_{\text {mag }}=m \cdot G(z, R)=m \cdot \frac{-3}{2} \cdot \mu \cdot \frac{R^{2} \cdot z}{\sqrt{\left(R^{2}+z^{2}\right)^{5}}} \cdot I,
$$

where $m$ is the magnetic momentum, $G(z, R)$ is the magnetic field gradient (along the axis perpendicular to the coil plane through the coil centre point), $\mu$ is the permeability of the medium between the permanent magnet and the coil, $R$ is the circular coil radius, $z$ is the distance between the magnet and the coil, and $I$ is the current. In a measurement obtained from 


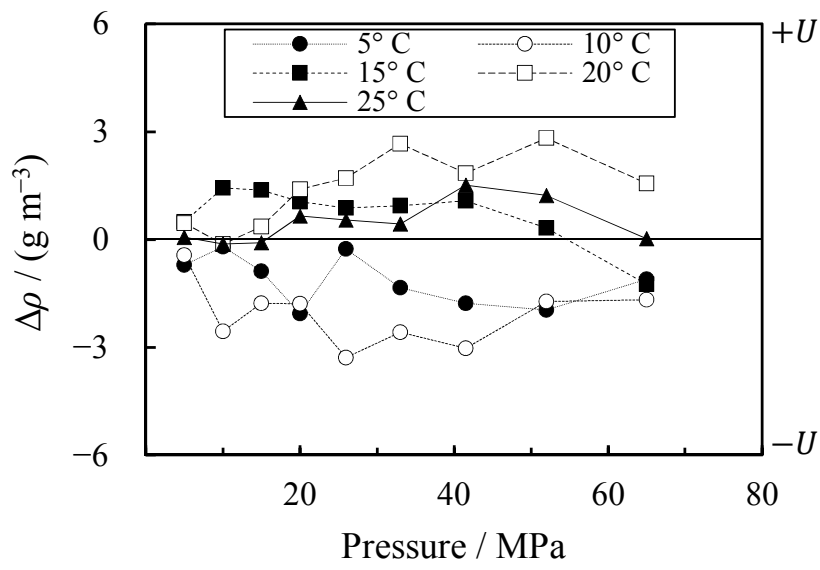

Figure 10. Deviation of measured from predicted seawater densities $\Delta \rho$ in the interpolation region at salinity 2. $U$ - uncertainty in the density-salinity relation.

seawater, the magnetic force is therefore dependent on the magnetic water properties and on the magnet-coil distance.

Bignell pointed out that the force on the magnet is also dependent on the magnetic field, even for magnetically hard materials. The magnetic force is therefore not linearly (as in Eq. 15) but quadratically dependent on the equilibrium current, i.e. $F_{\mathrm{mag}}=f_{1} \cdot I+f_{2} \cdot I^{2}$, where $f_{1}$ and $f_{2}$ are magnetic coupling constants. For a magnetically hard material, the force mainly depends on the linear term, whereas the quadratic term is used as a correction.

Millero et al. used a cylindrical (instead of a circular) coil and summarized the magnetic force as $F_{\mathrm{mag}}=f \cdot I$, where the calibration factor $f$ was determined with measurements obtained from air-saturated water by weighing the float with platinum weights. The seawater density was determined relative to water, i.e. relative to the calibration using water:

$\Delta \rho^{\mathrm{SW}}=\frac{f \cdot\left(I^{\mathrm{SW}}-I^{\mathrm{H}_{2} \mathrm{O}}\right)}{V+m_{\mathrm{Pt}} / \rho_{\mathrm{Pt}}}$,

where $I^{\mathrm{SW}}$ and $I^{\mathrm{H}_{2} \mathrm{O}}$ are the currents resulting from the measurements obtained from air-saturated seawater and water, $V$ is the float volume, which is also determined by the calibration, and $m_{\mathrm{Pt}}$ and $\rho_{\mathrm{Pt}}$ are the mass and density of the platinum weights, which were identical in a measurement obtained from seawater and water.

Since seawater and water have different magnetic properties, it is possible that the calibration factor $f$ is significantly different, i.e. $\mu^{\mathrm{SW}} \not \approx \mu^{\mathrm{H}_{2} \mathrm{O}} \Longrightarrow f^{\mathrm{SW}} \not f^{\mathrm{H}_{2} \mathrm{O}}$. To rule out this possibility, we carried out a representative calculation. Since, theoretically, $F_{\mathrm{mag}} \propto \mu \cdot I$ for a cylindring (and circular) ring coil, it follows directly that $\mu^{\mathrm{SW}} / \mu^{\mathrm{H}_{2} \mathrm{O}}=$ $f^{\mathrm{SW}} / f^{\mathrm{H}_{2} \mathrm{O}}$ if the permanent magnet is in the same position in both measurements; the calibration factor of seawater is thus calculated from that of water. The permeabilities are calculated by $\mu=\mu_{0} \cdot(1+\chi)$, where $\mu_{0}=4 \cdot \pi \cdot 10^{-7} \mathrm{NA}^{-2}$ is the vacuum permeability, $\chi^{\mathrm{SW}}=-8.25 \times 10^{-6}$, and $\chi^{\mathrm{H}_{2} \mathrm{O}}=$ $-9.04 \times 10^{-6}$ are the (dimensionless) volume susceptibilities of seawater with a salinity of 29 (Imhmed, 2012) and of water. The relative density deviation due to the different permeabilities being neglected was calculated by $\Delta \rho^{\mathrm{SW}}\left(f^{\mathrm{SW}}, f^{\mathrm{H}_{2} \mathrm{O}}\right)-\Delta \rho^{\mathrm{SW}}\left(f=f^{\mathrm{H}_{2} \mathrm{O}}\right)$ using (i) the calibration factor for water $f=f^{\mathrm{H}_{2} \mathrm{O}}=-3.5308 \mathrm{~g} \mathrm{~A}^{-1}$ for $25^{\circ} \mathrm{C}$ (Millero, 1967), (ii) the currents $I^{\mathrm{SW}}=0.4 \mathrm{~A}$ and $I^{\mathrm{H}_{2} \mathrm{O}}=0.15 \mathrm{~A}$, (iii) the platinum mass and density $m_{\mathrm{Pt}}=$ $0.7 \mathrm{~g}$ and $\rho_{\mathrm{Pt}}=21450 \mathrm{~kg} \mathrm{~m}^{-3}$, and (iv) the float volume given above. The values (ii) and (iii) were chosen based on a plot of calibration data of the flotation densimeter given by Millero (1967), and correspond to a relative seawater density of $28 \mathrm{~kg} \mathrm{~m}^{-3}$. The calculation yields a density deviation at the order of $0.01 \mathrm{~g} \mathrm{~m}^{-3}$; as a result, the differences in the magnetic properties of seawater and water are not problematic.

Since the volume of the float was also determined by means of the calibration measurement using water, it is possible that this resulted in a significant deviation in the relative seawater density. We therefore carried out a further representative calculation using the values (i-iv). Using this calculation, a density deviation of only $3 \mathrm{~g} \mathrm{~m}^{-3}$ is yielded for a relative volume deviation of $10^{-4}$. Although the volume results indirectly from an extrapolation of the linear relation of the magnetic coupling, $F_{\text {mag }}=f \cdot I$, which is quadratic even for magnetically hard materials according to Bignell (2006), it is unlikely that a volume deviation of this magnitude will occur in the calibration measurement; the float volume calibration is therefore not problematic.

We performed a final calculation to estimate how significant the precise height positioning of the permanent magnet is, i.e. the distance from the coil. Two reasons for a change of the distance are conceivable. On the one hand, the position of the magnet (inside the float) or of the coil can change in the time between the calibration measurement obtained from water and the measurement obtained from seawater; the permanent magnet was fixed in the hollow float using wax (Millero, 1967). Density deviations that result from such position changes are minimized if, after each measurement obtained from seawater, a measurement obtained from water had also been carried out (a quasi-substitution measurement). On the other hand, the "lift-off" process, wherein the equilibrium current is determined by sight, is not the same for seawater and water in terms of speed (among other factors). Density deviations that result from such dissimilarities are minimized, if, in additional to the "lift-off" current, the "drop-down" current had been determined in the opposite manner and both currents had been averaged for seawater and water, respectively. Or, if in the measurement obtained from seawater, the float was weighted with the aim to yield the same current as in the calibration measurement using water.

For the calculation, it was assumed that the height dependence of the magnetic force given by $z$ in Eq. (15) 

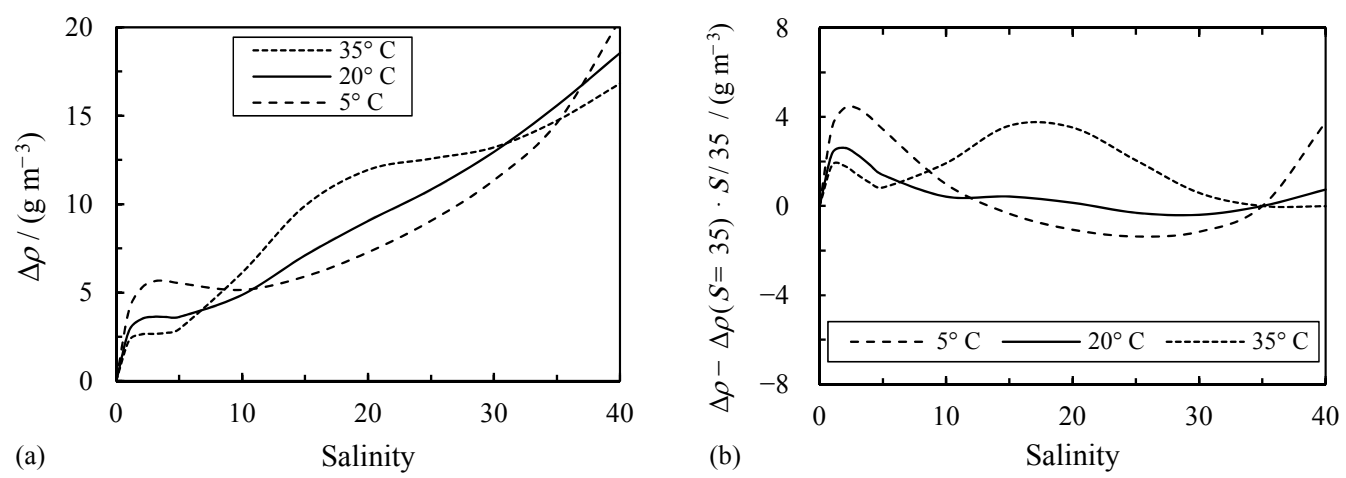

Figure 11. Density deviation of TEOS-10 from the density-salinity relation (i.e. TEOS-10 minus DSR) for degassed seawater at selected temperatures and atmospheric pressure. (a) The deviation $\Delta \rho$ increases linearly with salinity. The uncertainty in the deviation is $8 \mathrm{~g} \mathrm{~m}^{-3}$, and is significantly exceeded at salinities higher than 20. (b) By contrast, the salinity-35-reduced deviation is less than $5 \mathrm{~g} \mathrm{~m}^{-3}$.
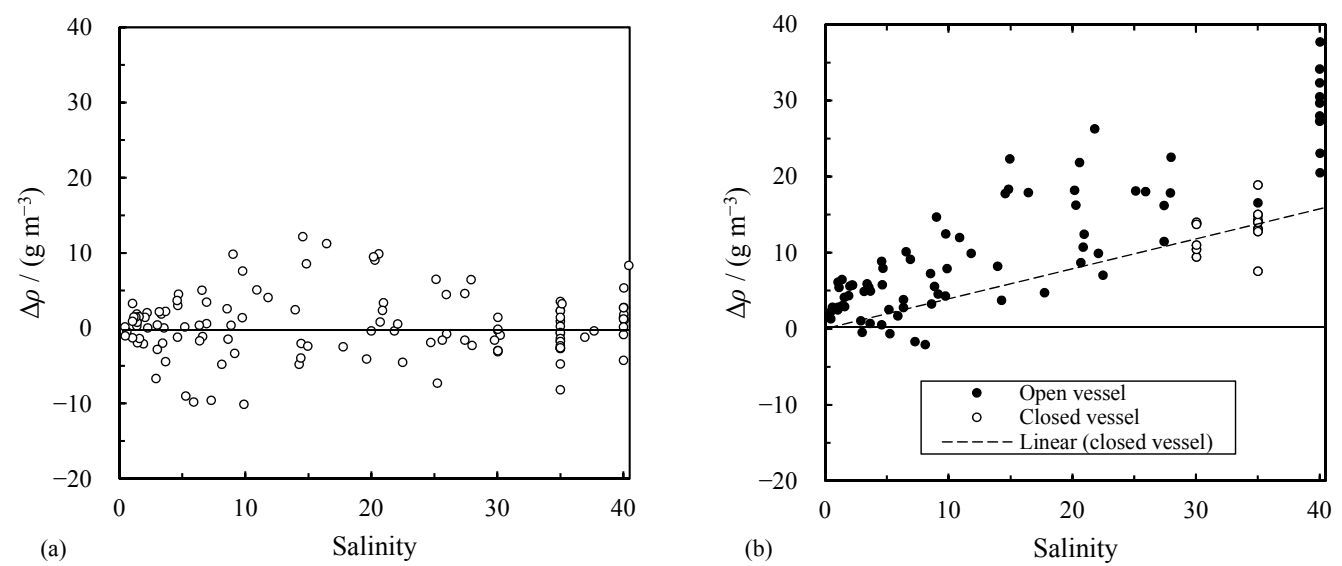

Figure 12. Deviation of densities obtained from standard seawater using a magnetic float densimeter by Millero et al. (a) The deviation of the normalized densities of Millero et al. (JPOTS, 1981c, pp. 51-56) from TEOS-10 (i.e. Millero et al. minus TEOS-10) suggest that TEOS-10 is well fitted to it. (b) The deviation of the original densities of Millero et al. (1976) (i.e. Millero et al. minus DSR) suggest a deviation that systematically increases with salinity. The density uncertainty calculated using the accuracy and reproducibility claimed by Millero et al. (1976) is $2 \mathrm{~g} \mathrm{~m}^{-3}$ and is significantly exceeded by most of the deviations.

for the circular coil is similar for the cylindrical coil used by Millero et al. (1976). If the distance between magnet and coil is $z+\Delta z$, then $f(z+\Delta z) / f(z)=(z+\Delta z) / z$. $\left[\left(R^{2}+z^{2}\right) /\left(R^{2}+(z+\Delta z)^{2}\right)\right]^{5 / 2}$ holds. The displacement of the coil or of the magnet can be treated mathematically as the same, since $f^{\mathrm{SW}}=f(z+\Delta z)$ applies to the measurement obtained from seawater and $f^{\mathrm{H}_{2} \mathrm{O}}=f(z)$ applies to the measurement obtained from water in both cases. Using the values (i-iv), the coil radius $R=20 \mathrm{~mm}$ and the distance $z=40 \mathrm{~mm}$ for an unconsidered distance increase in $\Delta z=3 \mu \mathrm{m}$ yield a relative seawater density which is too high by $10 \mathrm{~g} \mathrm{~m}^{-3} . R$ and $z$ were estimated based on a sketch and a dimension of the flotation densimeter used (Millero, 1967). If a temporal or permanent distance increase exists that is not considered, an approximately linear density increase (or decrease) as seen in Fig. 12b results.
The high sensitivity of the measurement density to the magnet height position is one reason why magnetic flotation densimeters that were developed later and that share a similar principle, e.g. that of Bignell (1982), use position sensing systems with accuracies that are at least in the micrometre range to keep the height, $z$, constant. The actual cause of the significance of the density deviations seen in Fig. 12a and b may therefore be an overestimation of the accuracy and precision of the magnetic flotation method used.

\subsection{High pressure}

TEOS-10 may be used to calculate densities for pressures up to $100 \mathrm{MPa}$. In the $\left(S, T, p>p_{0}\right)$-region of interest, the relative density data given by Chen and Millero (1976), as well as thermal expansion data given by Bradshaw and Schleicher (1970) and speed-of-sound data given by Del 
Grosso (1974) were used for fitting (Feistel, 2003, 2008). Chen and Millero (1976) directly measured the seawater density, i.e. the specific volume, relative to water using a magnetic float densimeter whose magnetic force on the float was determined as described above. By contrast, the data of Bradshaw and Schleicher (1970), and of Del Grosso (1974) allows only the calculation of density differences using thermodynamic relations, i.e. relative to a reference state of the absolute seawater density with defined salinity, temperature, and pressure.

An overview of the density deviation of TEOS-10 from the density-salinity relation in the entire salinity-temperature region for atmospheric pressure is given in Fig. 13a. The increase in the deviation with salinity seen in Fig. 11a for 5, 20 , and $35^{\circ} \mathrm{C}$ is also present for $0^{\circ} \mathrm{C}$. For higher temperatures and salinities of around 20, the deviation increases unexpectedly. A similar overview of the density deviation for $30 \mathrm{MPa}$ is given in Fig. 13b. The density deviation for this pressure is higher than that for atmospheric pressure. In the measurement region, this trend continues globally for up to $65 \mathrm{MPa}$ as seen in Fig. 13c, but, in the extrapolation region, discontinues locally for up to $100 \mathrm{MPa}$ as seen in Fig. 13d. For all pressures, the densities calculated using TEOS-10 are higher than the densities calculated using the density-salinity relation. The uncertainty in the deviations, however, is not exceeded significantly for higher pressures.

Chen and Millero measured the seawater density using a densimeter that is similar to that for atmospheric pressure used by Millero et al. (1976), which is why similar systematic deviations are likely. Both the thermal expansion data of Bradshaw and Schleicher and the speed-of-sound data of Del Grosso can only be compared with the density-salinity relation if the absolute seawater and water density are included in the calculation. The uncertainty in the water density calculated using IAPWS-95 is $10 \mathrm{~g} \mathrm{~m}^{-3}$ for pressures up to $10 \mathrm{MPa}$ and $30 \mathrm{~g} \mathrm{~m}^{-3}$ for up to $100 \mathrm{MPa}$. Since the deviation between TEOS-10 and the density-salinity relation shown in Fig. 13b-d is comparable to this uncertainty, the water density may be considered as a cause. For example, Lin and Trusler (2012) showed by rough calculation of the water density using their measured speed-of-sound data that the IAPWS- 95 density for 0 to $40^{\circ} \mathrm{C}$ and pressures up to $100 \mathrm{MPa}$ is within its uncertainty, but may be too low by a few $10 \mathrm{~g} \mathrm{~m}^{-3}$. A detailed analysis of this issue was given by Wagner and Thol (2015).

\section{Summary}

A density-salinity relation for IAPSO standard seawater was developed by means of highly accurate density measurements performed using a recently developed substitution method. This relation makes it possible to consistently determine (practical) salinity by means of density measurement at a level of accuracy that is comparable to that achieved by means of a conductivity measurement supported by PSS-78 and related application routines. The relation has been developed as a function of salinity, i.e. $\Delta \rho=f(S, T, p)$, relative to the density of water, as such a function was better fitted to the measurements, thereby increasing the accuracy of the predicted results. The relation is valid for seawater with the chemical salt composition of IAPSO standard seawater, for the isotopic water composition of Vienna Standard Mean Ocean Water, and for an air saturation of $100 \%$ at all temperatures and at atmospheric pressure. The reference density is that of degassed water. The measurement range comprises $\leq S \leq 35,5^{\circ} \mathrm{C} \leq T \leq 35^{\circ} \mathrm{C}$, and $0.1 \mathrm{MPa} \leq p \leq 65 \mathrm{MPa}$. In this range, the uncertainty in salinity (calculated from density) is 0.003 for atmospheric pressure and 0.008 for high pressures; the uncertainty in density (calculated from salinity) is 2 and $6 \mathrm{~g} \mathrm{~m}^{-3}$, respectively. Since the conditions occurring in the ocean cover a wider range, the relation range of validity has been extended to $\leq S \leq 40,0^{\circ} \mathrm{C} \leq T \leq 40^{\circ} \mathrm{C}$, and $0.1 \mathrm{MPa} \leq p \leq 100 \mathrm{MPa}$. In this range, the uncertainty was estimated to be a multiple of that in the measurement range, i.e. usually twice as much. A validation for temperatures down to $0{ }^{\circ} \mathrm{C}$ was performed using additional density measurements.

Density corrections for standard seawater were developed. Because the chemical composition was changed by interactions with borosilicate glass material of the storage vessel, and because the seawater samples used in the measurements were stored for different periods, the measured densities were corrected to a uniform (i.e. the original) chemical composition. These corrections are up to $3 \mathrm{~g} \mathrm{~m}^{-3}$. Because the isotopic water composition of the standard seawater changed due to the addition of water (with less deuterium, oxygen-17, and oxygen-18) in the preparation of dilute seawater samples, the measured densities were corrected to the uniform isotopic composition of VSMOW. These corrections are up to $2.5 \mathrm{~g} \mathrm{~m}^{-3}$. A further density correction was developed to correct the seawater air saturation to $100 \%$; where the temperature changed while air was excluded, the corrections were up to $1.5 \mathrm{~g} \mathrm{~m}^{-3}$. Taken together, all corrections total more than $5 \mathrm{~g} \mathrm{~m}^{-3}$.

The density-salinity relation was compared with the reference equation of state for seawater TEOS-10. For atmospheric pressure, density deviations of up to $15 \mathrm{~g} \mathrm{~m}^{-3}$ were found, which is significantly greater than the deviation uncertainty. Moreover, a systematic, linear dependence on salinity was found. One reason for the deviations is likely an overestimation of the accuracy of the density data that TEOS10 (as well as EOS-80) is based on in this region. For high pressures, density deviations of up to $40 \mathrm{~g} \mathrm{~m}^{-3}$ were found, which is of the same order of magnitude as the deviation uncertainty. 


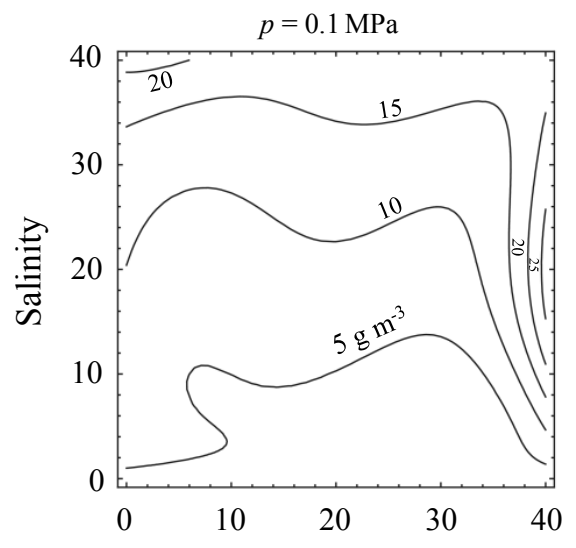

(a)

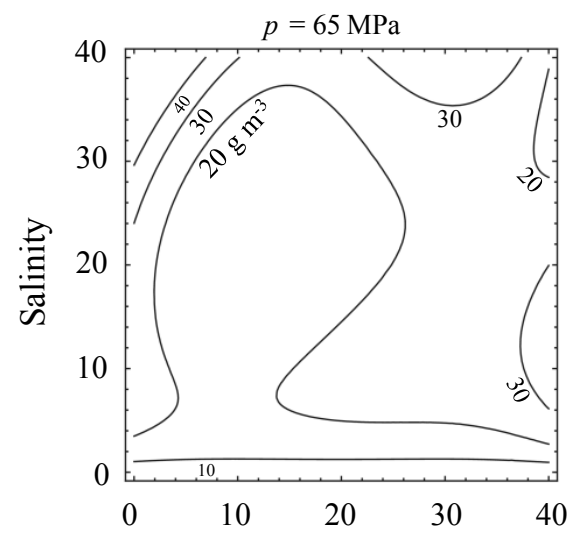

(c)
Temperature $/{ }^{\circ} \mathrm{C}$

Temperature $/{ }^{\circ} \mathrm{C}$

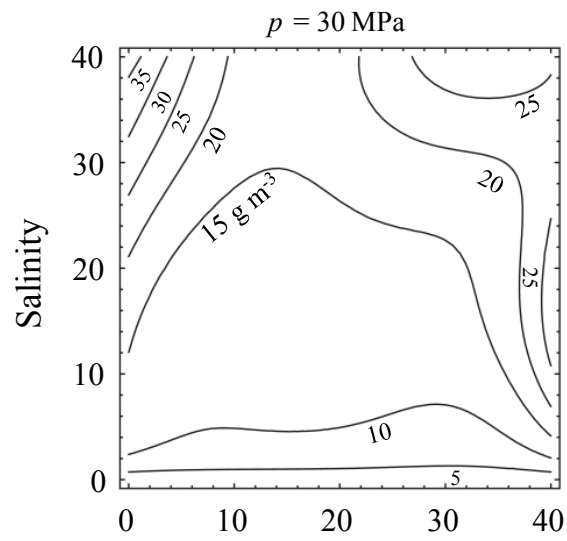

(b)

Temperature $/{ }^{\circ} \mathrm{C}$

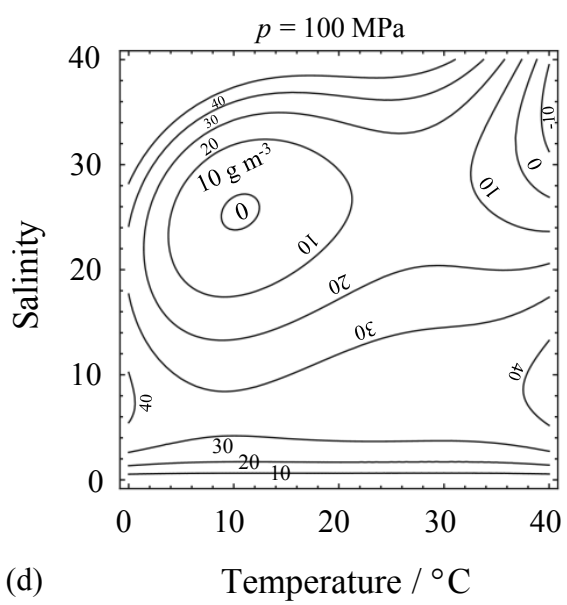

Figure 13. Density deviation of TEOS-10 from the density-salinity relation (i.e. TEOS-10 minus DSR) for degassed seawater (a) at atmospheric pressure, (b) at $30 \mathrm{MPa}$, (c) at $65 \mathrm{MPa}$, and (d) at $100 \mathrm{MPa}$. The uncertainties in the deviation are $8,26,26$, and $^{2} 3 \mathrm{~g} \mathrm{~m}^{-3}$. The deviations only exceed these uncertainties significantly at atmospheric pressure.

\section{Conclusions}

Seawater is changed during storage. Mainly silicon dioxide dissolves from borosilicate glass material and forms silicic acid, but over the long term, the solubility of other glass components is also important. This affects the density of stored seawater. If standard seawater is to be used as a density reference material, the solubility of all glass components must be quantified so that the change in the chemical composition and in density can be calculated. This also includes the dependence of this solution on temperature during storage; storage at low temperatures may minimize this interaction. For long-term storage, container materials that have a greater chemical resistance should be investigated.

Knowledge of the isotopic composition is essential for measurements obtained from seawater samples that are artificially diluted with water from different locations, as the local isotopic water composition varies significantly. For natural seawater, this may be important in marginal seas.

The data situation of recent highly accurate density measurements of standard seawater is poor, which is why further measurements should be carried out using state-of-the-art methods. The data of the density-salinity relation obtained in the present study should be used as a correction to TEOS10.

Salinity is usually measured by means of a salinometer measuring conductivity and by being calibrated by standard seawater, which is of natural origin. A long-term change in the salt proportions in seawater cannot be detected in this way, as it will be overwritten by the (re-)calibrations with standard seawater.

The density is sensitive to all components, including dissolved salts and gases (and even isotopes), and can be determined without natural reference materials. If the salt compo- 
sition of standard seawater is changing in the long term, the density-salinity relation provides a metrological basis for detecting this change.

As possible changes in the seawater density are expected to be of the order of measurement uncertainty or even smaller, a periodic assessment should be carried out over several decades. Since the introduction of the salinity determination using standard seawater, 40 years have passed without this. We propose a density measurement of any freshly prepared standard seawater batch. A well-known example of such a long-term assessment is the Keeling curve of the $\mathrm{CO}_{2}$ content in the atmosphere.
Data availability. The complete data used to develop and validate the density-salinity relation are provided in the Supplement. 


\section{Appendix A: Reference water density}

The calculation of the reference densities $\rho_{\text {ref }}^{\mathrm{H}_{2} \mathrm{O}}$ assigned to the water reference for the substitution measurements is based on the equation of state (EOS) given by Wagner and Pruß (2002), which was adopted by the International Association of the Properties of Water and Steam in 1995 as IAPWS-95:

$\rho_{0}^{\mathrm{H}_{2} \mathrm{O}}=\rho_{\text {IAPWS }-95}$,

where $\rho_{\text {IAPWS }-95}$ is valid for degassed water with VSMOW (IAEA, 2006) isotopic composition. The values calculated with this equation were therefore corrected to the air saturation and isotopic composition of our water reference to calculate its density accurately. The equation to correct for isotopic composition was taken from Tanaka et al. (2001) and is

$$
\frac{\Delta \rho_{\mathrm{c}}^{\mathrm{H}_{2} \mathrm{O}}\left(T_{\rho_{\max }}, p_{0}\right)}{\mathrm{g} \mathrm{m}^{-3}}=0.233 \cdot \frac{\delta_{18}}{\% o}+0.0166 \cdot \frac{\delta_{\mathrm{D}}}{\% o},
$$

where $\Delta \rho_{\mathrm{c}}^{\mathrm{H}_{2} \mathrm{O}}$ is the density difference due to isotopic composition, $\delta_{\mathrm{D}}$ and $\delta_{18}$ are the isotopic abundances of deuterium and oxygen-18 relative to VSMOW composition, $T_{\rho_{\max }}=3.98^{\circ} \mathrm{C}$ (at maximum density), and $p_{0}=101325 \mathrm{~Pa}$.

The correction for air saturation was taken from Harvey et al. (2005) and is (valid for 0 to $50^{\circ} \mathrm{C}$ and $101325 \mathrm{~Pa}$ )

$$
\begin{aligned}
\frac{\Delta \rho_{\mathrm{a}}^{\mathrm{H}_{2} \mathrm{O}}\left(T, p_{0}\right)}{\mathrm{g} \mathrm{m}^{-3}}= & 0.103-2.371 \times 10^{5} \cdot\left(\frac{T}{{ }^{\circ} \mathrm{C}}+75\right)^{-2.5} \\
& +1.82 \times 10^{-7} \cdot\left(\frac{T}{{ }^{\circ} \mathrm{C}}+75\right)^{3},
\end{aligned}
$$

where $\Delta \rho_{\mathrm{a}}^{\mathrm{H}_{2} \mathrm{O}}$ is the density difference due to air saturation and $T$ is the temperature.

We assumed the corrections for isotopic composition and air saturation are dependent on temperature and pressure and applied corrections in the following manner:

$\Delta \rho_{\mathrm{c}}^{\mathrm{H}_{2} \mathrm{O}}(T, p)=\frac{\Delta \rho_{0}^{\mathrm{H}_{2} \mathrm{O}}(T, p)}{\Delta \rho_{0}^{\mathrm{H}_{2} \mathrm{O}}\left(T_{\rho_{\max }}, p_{0}\right)} \cdot \Delta \rho_{\mathrm{c}}^{\mathrm{H}_{2} \mathrm{O}}\left(T_{\rho_{\max }}, p_{0}\right)$

and

$$
\Delta \rho_{\mathrm{a}}^{\mathrm{H}_{2} \mathrm{O}}(T, p)=\frac{\Delta \rho_{0}^{\mathrm{H}_{2} \mathrm{O}}(T, p)}{\Delta \rho_{0}^{\mathrm{H}_{2} \mathrm{O}}\left(T, p_{0}\right)} \cdot \Delta \rho_{\mathrm{a}}^{\mathrm{H}_{2} \mathrm{O}}\left(T, p_{0}\right),
$$

where the corrections are scaled to the density of water with VSMOW isotopic composition based on their valid states of temperature $T$ and pressure $p$. The water reference density is consequently given by

$\rho_{\text {ref }}^{\mathrm{H}_{2} \mathrm{O}}=\rho_{0}^{\mathrm{H}_{2} \mathrm{O}}+\Delta \rho_{\mathrm{c}}^{\mathrm{H}_{2} \mathrm{O}}+\Delta \rho_{\mathrm{a}}^{\mathrm{H}_{2} \mathrm{O}}$.

Uncertainties for the calculated densities $\rho_{\text {IAPWS }-95}$ relevant for the temperature range of 5 to $35^{\circ} \mathrm{C}$ given by Wagner and Pruß are $1 \mathrm{~g} \mathrm{~m}^{-3}$ for atmospheric pressure, $10 \mathrm{~g} \mathrm{~m}^{-3}$ for pressures up to $10 \mathrm{MPa}$, and $30 \mathrm{~g} \mathrm{~m}^{-3}$ for pressures up to $100 \mathrm{MPa}$. The uncertainties of corrections for isotopic composition and air saturation including the measurements and calculations contribute $10 \%$ to the overall uncertainty in the seawater density measurements at atmospheric pressure (Schmidt et al., 2016).

\section{Appendix B: Relation uncertainty}

The density-salinity relation is an empirical thermophysical equation of state, the formulation of which is determined by the underlying measurement values and their associated uncertainties, which were determined in accordance with the Guide to the Expression of Uncertainty in Measurement (GUM) adopted by the Joint Committee for Guides in Metrology (JCGM) in 2008 (JCGM GUM, 2008).

To calculate the uncertainty in predicted results of the density-salinity relation, the Monte Carlo method (MCM) as described in Supplement 2 to the GUM (JCGM GUM S2, 2011) was applied. In the MCM, $n=15000$ random values (for atmospheric and high pressures) of each particular measurement value were generated based on the associated uncertainty distribution; in the case of the relative density values $\Delta \rho_{0}$ and $\Delta \Delta \rho_{0}$, this is a $t$-distribution. The result is a data set with $n$ subsets that are used to fit the equation coefficients $n$ times. The final value of a coefficient is obtained by calculating the mean value of all (random) coefficient values resulting from the $n$ fits. The standard uncertainty in a coefficient is obtained by calculating the standard deviation. For calculation of the uncertainty in a predicted value, the correlations between the fit coefficients have to be taken into account. These are obtained by calculating the particular empirical correlation coefficients using the random data.

Since the applicability of MCM described in the GUM S2 is by definition limited to measurement models that usually involve the use of physical laws, the uncertainty in a predicted value determined in this way may not be consistent. For this reason, the consistency of the predicted uncertainties has to be evaluated.

A common approach to evaluate the consistency of a fit equation is to compare the values of the fit residual $\Delta$ against their associated uncertainty $U(\Delta)$. A particular $U(\Delta)$ is calculated using the law of propagation of uncertainty:

$U(\Delta)=$

$\sqrt{U\left(\Delta \rho_{\mathrm{m}}\right)^{2}+U\left(\Delta \rho_{\mathrm{p}}\right)^{2}+2 \cdot U\left(\Delta \rho_{\mathrm{m}}\right) \cdot U\left(\Delta \rho_{\mathrm{p}}\right) \cdot r\left(\Delta \rho_{\mathrm{m}}, \Delta \rho_{\mathrm{p}}\right)}$,

where $r\left(\Delta \rho_{\mathrm{m}}, \Delta \rho_{\mathrm{p}}\right)$ is the empirical correlation coefficient of the predicted and measured values. Because in the fit process e.g. the residual sum of squares (RSS) is minimized, the predicted and measured densities are necessarily correlated; hence, $r\left(\Delta \rho_{\mathrm{m}}, \Delta \rho_{\mathrm{p}}\right) \neq 0$. Since this is commonly not considered in the consistency verification, the uncertainty 
in predicted values may be overestimated or underestimated (Schmidt, 2017). The correlation coefficient $r\left(\Delta \rho_{\mathrm{m}}, \Delta \rho_{\mathrm{p}}\right) \neq$ 0 was obtained by calculating the predicted value $n$ times using the $n$ subsets of the fit coefficients gained with the MCM described above.

Next, every calculated residual uncertainty at a probability of $95.45 \%$ was compared to the corresponding residual to evaluate the uncertainty, which is associated with the predicted value. In the case of the density-salinity relation consistency verification, $95.45 \%$ of the residuals had to be smaller than their associated uncertainties; thus, $|\Delta|=$ $\left|\Delta \rho_{\mathrm{m}}-\Delta \rho_{\mathrm{p}}\right| \leq U(\Delta)$. When this was not the case and more than $4.55 \%$ of the residuals were higher than their corresponding uncertainties, the uncertainty in the predicted value was increased gradually until the criterion was fulfilled. The increased uncertainty was then adopted for any predicted value in the corresponding atmospheric or high-pressure region. 


\section{The Supplement related to this article is available online at https://doi.org/10.5194/os-14-15-2018-supplement.}

Competing interests. The authors declare that they have no conflict of interest.

Acknowledgements. This work was funded by the European Metrology Research Programme, EMRP Project ENV05. The EMRP is jointly funded by the EMRP participating countries within EURAMET and the European Union.

The authors greatly value the silicate concentration measurements obtained from seawater performed by Kai-Uwe Ludwichowski at the Alfred-Wegener-Institut, Helmholtz-Zentrum für Polar- und Meeresforschung (AWI), and would like to thank Gereon Budéus (AWI) for valuable discussions on oceanographic matters.

This article contributes to the tasks of the Joint SCOR/IAPWS/IAPSO Committee on the Properties of Seawater (JCS).

Edited by: Mario Hoppema

Reviewed by: two anonymous referees

\section{References}

Bacon, S., Culkin, F., Higgs, N., and Ridout, P.: IAPSO standard seawater: definition of the uncertainty in the calibration procedure and stability of recent batches, J. Atmos. Ocean. Tech., 24, 1785-1799, https://doi.org/10.1175/JTECH2081.1, 2007.

Bignell, N.: A magnetic float densimeter for the measurement of changes in water density on aeration, J. Phys. E Sci. Instrum., 15, 378-381, https://doi.org/10.1088/0022-3735/15/3/031, 1982.

Bignell, N.: The effect of dissolved air on the density of water, Metrologia, 19, 57-59, https://doi.org/10.1088/00261394/19/2/002, 1983.

Bignell, N.: Magnetic flotation in densimetry, Meas. Sci. Technol., 17, 2574-2580, https://doi.org/10.1088/0957-0233/17/10/007, 2006.

Bradshaw, A.: The effect of carbon dioxide on the specific volume of seawater, Limnology and Oceanography, 18, 95-105, https://doi.org/10.4319/LO.1973.18.1.0095, 1973.

Bradshaw, A. and Schleicher, K. E.: Direct measurement of thermal expansion of sea water under pressure, Deep-Sea Res., 17, 691706, https://doi.org/10.1016/0011-7471(70)90035-5, 1970.

Bradshaw, A. and Schleicher, K.: Electrical conductivity of seawater, IEEE J. Ocean. Eng., 5, 50-62, https://doi.org/10.1109/JOE.1980.1145449, 1980.

Chen, C.-T. and Millero, F. J.: The specific volume of seawater at high pressure, Deep-Sea Res., 23, 595-612, https://doi.org/10.1016/0011-7471(76)90003-6, 1976.

Consultative Committee for Thermometry (CCT): Techniques for approximating the international temperature scale of 1990, 1997 reprint of 1990 first edition, BIPM, Sèvres, France, available at: http://www.bipm.org/utils/common/pdf/ ITS-90/ITS-90-Techniques-for-Approximating.pdf (last access: 17 August 2017), 1997.
Corning Inc.: PYREX ${ }^{\circledR}$ and Corning ${ }^{\circledR}$ glass and reusable plastic product selection guide, Tewksbury, MA, USA, CLS-GL-001 REV9, available at: https://www.corning.com/media/worldwide/ cls/documents/CLS-GL-001REV9.pdf (last access: 17 August 2017), 2014.

Culkin, F.: Calibration of standard seawater in electrical conductivity, Sci. Total Environ., 49, 1-7, https://doi.org/10.1016/00489697(86)90230-5, 1986.

Culkin, F. and Smith, N.: Determination of the concentration of potassium chloride solution having the same electrical conductivity, at $15^{\circ} \mathrm{C}$ and infinite frequency, as standard seawater of salinity $35.0000 \%$ (chlorinity $19.37394 \%$ o), IEEE J. Oceanic Eng., OE-5, 22-23, https://doi.org/10.1109/JOE.1980.1145443, 1980.

Darling, W. G., Bath, A. H., and Talbot, J. C.: The O and H stable isotope composition of freshwaters in the British Isles. 2. Surface waters and groundwater, Hydrol. Earth Syst. Sci., 7, 183-195, https://doi.org/10.5194/hess-7-183-2003, 2003.

Dauphinee, T. M., Ancsin, J., Klein, H. P., and Phillips, M. J.: The electrical conductivity of weight diluted and concentrated standard seawater as a function of salinity and temperature, IEEE J. Oceanic Eng., OE-5, 28-41, https://doi.org/10.1109/JOE.1980.1145439, 1980a.

Dauphinee, T. M., Ancsin, J., Klein, H. P., and Phillips, M. J.: The effect of concentration and temperature on the conductivity ratio of potassium chloride solutions to standard seawater of salinity $35 \%$ ( Cl 19.3740\%o), IEEE J. Oceanic Eng., OE-5, 17-21, https://doi.org/10.1109/JOE.1980.1145444, 1980b.

Del Grosso, V. A.: New equation for the speed of sound in natural waters (with comparison to other equations), J. Acoust. Soc. Am., 32, 285-300, https://doi.org/10.1121/1.1903388, 1974.

Dickson, A. G.: Standard potential of the reaction $\mathrm{AgCl}(\mathrm{s})+$ $\frac{1}{2} \mathrm{H}_{2}(\mathrm{~g})=\mathrm{Ag}(\mathrm{s})+\mathrm{HCl}(\mathrm{aq})$ and the standard acidity constant of the ion $\mathrm{HSO}_{4}^{-}$in synthetic sea water from 273.15 to $318.15 \mathrm{~K}$, J. Chem. Thermodyn., 22, 113-127, https://doi.org/10.1016/00219614(90)90074-Z, 1990.

DURAN Group GmbH: DURAN ${ }^{\circledR}$ precision bore tubing, Wertheim, Germany, 50098 d 09078.0 ba/dh, available at: http://www.duran-group.com/uploads/tx_fedownloads/ DURAN_Precision_bore_tubing_E.pdf (last access: 17 August 2017), 2009.

Feistel, R.: A new extended Gibbs thermodynamic potential of seawater, Prog. Oceanogr., 58, 43-114, https://doi.org/10.1016/S0079-6611(03)00088-0, 2003.

Feistel, R.: A Gibbs function for seawater thermodynamics for -6 to $80^{\circ} \mathrm{C}$ and salinity up to $120 \mathrm{~g} / \mathrm{kg}$, Deep-Sea Res. Pt. I, 55, 1639-1671, https://doi.org/10.1016/j.dsr.2008.07.004, 2008.

Ferronsky, V. I. and Polyakov, V. A.: Isotopes of the Earth's hydrosphere, Springer, Dordrecht, Netherlands, https://doi.org/10.1007/978-94-007-2856-1, 2012.

Garcia, H. E. and Gordon, L. I.: Oxygen solubility in seawater - Better fitting equations, Limnol. Oceanogr., 37, 1307-1312, https://doi.org/10.4319/lo.1992.37.6.1307, 1992.

Grambow, B.: A general rate equation for nuclear waste glass corrosion, Mater. Res. Soc. Symp. P., 44, 15-27, https://doi.org/10.1557/PROC-44-15, 1985.

Grasshoff, K., Kremling, K., and Ehrhardt, M.: Methods of seawater analysis, 3, Wiley-VCH, Weinheim, Germany, https://doi.org/10.1002/9783527613984, 1999. 
Hamme, R. C. and Emerson, S. R.: The solubility of neon, nitrogen and argon in distilled water and seawater, Deep-Sea Res. Pt. I, 51, 1517-1528, https://doi.org/10.1016/j.dsr.2004.06.009, 2004.

Harvey, A. H., Kaplan, S. G., and Burnett, J. H.: Effect of dissolved air on the density and refractive index of water, Int. J. Thermophys., 26, 1495-1514, https://doi.org/10.1007/s10765005-8099-0, 2005.

Higgs, N. and Ridout, P.: Future Requirements for IAPSO standard seawater - The IAPSO standard seawater service, Ocean Scientific International Limited, Havant, UK, available at: https://www.ptb.de/cms/fileadmin/internet/fachabteilungen/ abteilung_3/3.1_metrologie_in_der_chemie/aktuell/env05/ PTB_presentation_120911.pdf (last access: 17 August 2017), 2011.

Imhmed, S. A. A.: Application of magnetic susceptibility measurements to oilfield scale management, $\mathrm{PhD}$ thesis, Institute of Petroleum Engineering, Heriot-Watt University, Edinburgh, Scotland, UK, available at: http://www.ros.hw.ac.uk/bitstream/ handle/10399/2564/ImhmedSAA_0412_pe.pdf (last access: 17 August 2017), 2012.

International Atomic Energy Agency (IAEA): Vienna Standard Mean Ocean Water (VSMOW) and Standard Light Antarctic Precipitation (SLAP) water, Reference Sheet for International Measurement Standards (1 Dec 2006), available at: https://nucleus. iaea.org/rpst/documents/vsmow_slap.pdf (last access: 17 August 2017), 2006.

IOC, SCOR and IAPSO: The international thermodynamic equation of seawater-2010: Calculation and use of thermodynamic properties, Intergovernmental Oceanographic Commission, Manuals and Guides, 56, UNESCO, Paris, France, available at: http: //unesdoc.unesco.org/images/0019/001930/193020e.pdf (last access: 17 August 2017), 2010.

Joint Committee for Guides in Metrology (JCGM GUM): JCGM 100-2008 Evaluation of measurement data - Guide to the expression of uncertainty in measurement, BIPM, IEC, IFCC, ILAC, ISO, IUPAC, IUPAP, OIML, available at: http://www.bipm.org/ en/publications/guides/gum.html (last access: 17 August 2017), 2008.

Joint Committee for Guides in Metrology (JCGM GUM S2): JCGM 102:2011 Evaluation of measurement data - Supplement 2 to the "Guide to the expression of uncertainty in measurement" - Extension to any number of output quantities, BIPM, IEC, IFCC, ILAC, ISO, IUPAC, IUPAP, OIML, available at: http://www. bipm.org/en/publications/guides/gum.html (last access: $17 \mathrm{Au}-$ gust 2017), 2011.

Joint Panel on Oceanographic Tables and Standards (JPOTS): Tenth report of the Joint Panel on Oceanographic Tables and Standards - The Practical Salinity Scale 1978 and The International Equation of State of Seawater 1980, Unesco technical papers in marine science, 36, 13-17, UNESCO, Paris, France, available at: http://unesdoc.unesco.org/images/0004/ 000461/046148eb.pdf (last access: 17 August 2017), 1981a.

Joint Panel on Oceanographic Tables and Standards (JPOTS): Background papers and supporting data on the Practical Salinity Scale 1978, Unesco technical papers in marine science, 37, UNESCO, Paris, France, available at: http://unesdoc.unesco. org/images/0004/000479/047932eb.pdf (last access: 17 August 2017), 1981b.
Joint Panel on Oceanographic Tables and Standards (JPOTS): Background papers and supporting data on the International Equation of State of Seawater 1980, Unesco technical papers in marine science, 38, UNESCO, Paris, France, available at: http:// unesdoc.unesco.org/images/0004/000479/047932eb.pdf (last access: 17 August 2017), 1981c.

Lee, K., Kim, T. W., Byrne, R. H., Millero, F. J., Feely, R. A. and Liu, Y. M.: The universal ratio of boron to chlorinity for the North Pacific and North Atlantic oceans, Geochim. Cosmochim. Ac., 74, 1801-11, https://doi.org/10.1016/J.GCA.2009.12.027, 2010.

Le Menn, M.: About uncertainties in practical salinity calculations, Ocean Sci., 7, 651-659, https://doi.org/10.5194/os-7-651-2011, 2011.

Lin, C.-W. and Trusler, J. P. M.: The speed of sound and derived thermodynamic properties of pure water at temperatures between (253 and 473) $\mathrm{K}$ and at pressures up to $400 \mathrm{MPa}$, J. Chem. Phys., 136, 094511, https://doi.org/10.1063/1.3688054, 2012.

Millero, F. J.: High precision magnetic float densimeter, Rev. Sci. Instrum., 38, 1441-1444, https://doi.org/10.1063/1.1720558, 1967.

Millero, F. J.: The marine inorganic carbon cycle, Chem. Rev., 107, 308-341, https://doi.org/10.1021/cr0503557, 2007.

Millero, F. J.: Carbonate constants for estuarine waters, Mar. Freshwater Res., 61, 139-142, https://doi.org/10.1071/MF09254, 2010.

Millero, F. J., Gonzalez, A., and Ward, G. K.: The density of seawater solutions at one atmosphere as a function of temperature and salinity, J. Marine Res., 34, 61-93, 1976.

Millero, F. J., Feistel, R., Wright, D. G., and McDougall, T. J.: The composition of standard seawater and the definition of the reference-composition salinity scale, Deep-Sea Res. Pt. I, 55, 50-72, https://doi.org/10.1016/j.dsr.2007.10.001, 2008.

Ohsumi, T., Nakashiki, T., Shitashima, K., and Hirama, K.: Density change of water due to dissolution of carbon dioxide and nearfield behavior of $\mathrm{CO}_{2}$ from a source on deep-sea floor, Energ. Convers. Manage., 33, 685-690, https://doi.org/10.1016/01968904(92)90072-5, 1992.

Ostlund, H. G., Craig, H., Broecker, W. S., and Spenser, D.: GEOSECS Atlantic, Pacific and Indian Ocean expeditions: shorebased data and graphics, Washington, D. C., USA, available at: http://epic.awi.de/34890/1/ atlantic-pacific-indian-ocean-expedition_vol7.pdf (last access: 17 August 2017), 1987.

Pawlowicz, R., Feistel, R., McDougall, T. J., Ridout, P., Seitz, S., and Wolf, H.: Metrological challenges for measurements of key climatological observables - Part 2: Oceanic salinity, Metrologia, 53, R12-R15, https://doi.org/10.1088/0026-1394/53/1/R12, 2016.

Perkin, R. G. and Lewis, E. L.: The Practical Salinity Scale 1978 - Fitting the data, IEEE J. Oceanic Eng., OE-5, 9-16, https://doi.org/10.1109/JOE.1980.1145441, 1980.

Poisson, A.: Conductivity, salinity, temperature relationship of diluted and concentrated standard seawater, IEEE J. Oceanic Eng., OE-5, 41-50, https://doi.org/10.1109/JOE.1980.1145442, 1980a.

Poisson, A.: The concentration of the $\mathrm{KCl}$ solution whose conductivity is that of standard seawater $\left(35 \%\right.$ ) at $15^{\circ} \mathrm{C}$, IEEE J. Oceanic Eng., OE-5 24-28, https://doi.org/10.1109/JOE.1980.1145440, 1980 b. 
Poisson, A., Dauphinee, T., Ross, C. K., and Culkin, F.: The reliability of standard seawater as an electrical conductivity standard, Oceanol. Acta, 1, 425-433, 1978.

Poisson, A., Brunet, C., and Brun-Cottan, J. C.: Density of standard seawater solutions at atmospheric pressure, Deep-Sea Res., 27A, 1013-1028, https://doi.org/10.1016/0198-0149(80)90062X, 1980

Robbins, L. L., Hansen, M. E., Kleypas, J. A., and Meylan, S. C.: $\mathrm{CO}_{2}$ calc - Seawater carbon calculator, U.S. Geological Survey, Open-File Report 2010-1280, 2010.

Schmidt, H.: Consistency verification of equations of state Significance of the correlation between measured and predicted data, Thermophysical Properties for Technical Thermodynamics (THERMAM), Rostock, Germany, 17-18 July 2017, 978-3941554-17-7, https://doi.org/10.13140/RG.2.2.10997.06888, 2017.

Schmidt, H., Wolf, H., and Hassel, E.: A method to measure the density of seawater accurately to the level of $10^{-6}$, Metrologia, 53, 770-786, https://doi.org/10.1088/0026-1394/53/2/770, 2016.

Seitz, S., Spitzer, P., and Brown, R. J. C.: CCQM-P111 study on traceable determination of practical salinity and mass fraction of major seawater components, Accredit. Qual. Assur., 15, 9-17, https://doi.org/10.1007/s00769-009-0578-8, 2010.

Seitz, S., Feistel, R., Wright, D. G., Weinreben, S., Spitzer, P., and De Bièvre, P.: Metrological traceability of oceanographic salinity measurement results, Ocean Sci., 7, 45-62, https://doi.org/10.5194/os-7-45-2011, 2011.
Song, Y., Chen, B., Nishio, M., and Akai, M: The study on density change of carbon dioxide seawater solution at high pressure and low temperature, Energy, 30, 2298-2307, https://doi.org/10.1016/j.energy.2003.10.022, 2005.

Tanaka, M., Girard, G., Davis, R., Peuto, A., and Bignell, N.: Recommended table for the density of water between $0^{\circ} \mathrm{C}$ and $40^{\circ} \mathrm{C}$ based on recent experimental reports, Metrologia, 38, 301-309, https://doi.org/10.1088/0026-1394/38/4/3, 2001.

Uchida, H., Kawano, T., Aoyama, M., and Murata, A.: Absolute salinity measurements of standard seawaters for conductivity and nutrients, La mer, 49, 119-126, 2011.

Wagner, W. and Pruß, A.: The IAPWS formulation 1995 for the thermodynamic properties of ordinary water substance for general and scientific use, J. Phys. Chem. Ref. Data, 31, 387-535, https://doi.org/10.1063/1.1461829, 2002.

Wagner, W. and Thol, M.: The behaviour of IAPWS-95 from 250 to $300 \mathrm{~K}$ and pressures up to $400 \mathrm{MPa}$ - Evaluation based on recently derived property data, J. Phys. Chem. Ref. Data, 44, 043102-1-40, https://doi.org/10.1063/1.4931475, 2015.

Wolf, H.: Determination of water density - Limitations at the uncertainty level of $1 \times 10^{-6}$, Accredit. Qual. Assur., 13, 587-591, https://doi.org/10.1007/s00769-008-0442-2, 2008.

Zeebe, R. E. und Wolf-Gladrow, D.: $\mathrm{CO}_{2}$ in seawater - Equilibrium, kinetics, isotopes, 1st Edn., Oceanography Series Vol. 65, Elsevier, Amsterdam, 360 pp. , 2001. 